\title{
Microglia Regulate the Number of Neural Precursor Cells in the Developing Cerebral Cortex
}

\author{
Christopher L. Cunningham, ${ }^{1}$ Verónica Martínez-Cerdeño, ${ }^{1,2,3,5}$ and Stephen C. Noctor ${ }^{1,4,5}$ \\ ${ }^{1}$ Neuroscience Graduate Program, University of California, Davis, ${ }^{2}$ Institute for Pediatric Regenerative Medicine, Shriners Hospital for Children of Northern \\ California, Departments of ${ }^{3}$ Pathology and Laboratory Medicine, and ${ }^{4}$ Psychiatry and Behavioral Sciences, and the ${ }^{5}$ MIND Institute, University of \\ California, Davis, Sacramento, California 95817
}

\begin{abstract}
Neurogenesis must be properly regulated to ensure that cell production does not exceed the requirements of the growing cerebral cortex, yet our understanding of mechanisms that restrain neuron production remains incomplete. We investigated the function of microglial cells in the developing cerebral cortex of prenatal and postnatal macaques and rats and show that microglia limit the production of cortical neurons by phagocytosing neural precursor cells. We show that microglia selectively colonize the cortical proliferative zones and phagocytose neural precursor cells as neurogenesis nears completion. We found that deactivating microglia in utero with tetracyclines or eliminating microglia from the fetal cerebral cortex with liposomal clodronate significantly increased the number of neural precursor cells, while activating microglia in utero through maternal immune activation significantly decreased the number of neural precursor cells. These data demonstrate that microglia play a fundamental role in regulating the size of the precursor cell pool in the developing cerebral cortex, expanding our understanding of the mechanisms that regulate cortical development. Furthermore, our data suggest that any factor that alters the number or activation state of microglia in utero can profoundly affect neural development and affect behavioral outcomes.
\end{abstract}

\section{Introduction}

The human cerebral cortex is populated by $20-25$ billion neurons (Pelvig et al., 2008) that are generated in the ventricular zone (VZ) and subventricular zone (SVZ) during prenatal development (Rakic, 2009; Lui et al., 2011). Regulation of proliferation is critical for ensuring that cell production meets but does not exceed demand in the developing cerebral cortex. Mechanisms that amplify the number of neural precursor cells, and hence the number of cortical neurons generated, have been identified in the rodent (Noctor et al., 2004; Noctor et al., 2008) and primate cortex (Hansen et al., 2010; Fietz et al., 2010). Yet we know comparatively little of the mechanisms that restrain cell production, or that reduce the size of the precursor cell pool, particularly during end stages of cortical neurogenesis. Unrestrained cell production during prenatal brain development would have profoundly negative consequences for brain organization and function. However, through what mechanism(s) is cell prolifer-

Received July 18, 2012; revised 0ct. 26, 2012; accepted Nov. 26, 2012.

Author contributions: C.L.C., V.M.-C., and S.C.N. designed research; C.L.C., V.M.-C., and S.C.N. performed research;V.M.-C. and S.C.N. contributed unpublished reagents/analytic tools; C.L.C., V.M.-C., and S.C.N. analyzed data; C.L.C., V.M.-C., and S.C.N. wrote the paper.

This work was supported by the MIND Institute, Children's Miracle Network, National Science Foundation, and National Institutes of Health. We thank Drs. David Amaral, Frank Sharp, Lee-Way Jin and Paul Ashwood for comments on this manuscript. We thank Dr. David Amaral for the macaque tissue and Dr. Gimenez Amaya for fetal human tissue. We thank Anish Prakash, Magi Aurora, Mitchell Quinton, Craig Jarvis, Elliott Weideman, Virgil Ricks, Jeanelle Ariza, and Craig Stewart for technical assistance; Dr. Paul Ashwood and Milo Careaga for LPS and primary antibodies; Drs. Robert Berman, Frank Sharp, and James Angelastro for tetracyclines and Dox Chow; Manuel Kukuljan for pCAG-DsRed, and Drs. David Pleasure, Peter Bannerman, and Athena Soulika for primary antibodies.

The authors declare no competing financial interests.

Correspondence should be addressed to Dr. Stephen C. Noctor, UC Davis MIND Institute, 2805 50th Street, Sacramento, CA 95817. E-mail: scnoctor@ucdavis.edu.

DOI:10.1523/JNEUROSCI.3441-12.2013

Copyright $\odot 2013$ the authors $\quad 0270-6474 / 13 / 334216-18 \$ 15.00 / 0$ ation restrained? Microglial cells colonize the cerebral cortex during prenatal development (Andjelkovic et al., 1998; Rezaie and Male, 1999; Verney et al., 2010; Swinnen et al., 2012), and comprise $\sim 5-6 \%$ of all cortical cells (Pelvig et al., 2008). Despite recent progress elucidating the function of microglia in the developing CNS (Deverman and Patterson, 2009; Pont-Lezica et al., 2011; Tremblay et al., 2011) and a wealth of knowledge on microglial function in the mature brain (Kreutzberg, 1996; Kettenmann et al., 2011; Saijo and Glass, 2011), the functional roles of microglia during prenatal cortical development are not well understood. We show here that microglia colonize the neural proliferative zones in the developing neocortex of rodent, monkey, and human and phagocytose neural precursor cells, particularly during late stages of cortical neurogenesis. We demonstrate that the vast majority of microglia in the developing prenatal and postnatal cerebral cortex have an activated morphology and express markers associated with activation. We also show that augmenting in utero activation of fetal microglia through maternal immune activation (MIA) decreases the number of neural precursor cells, and that in utero deactivation or elimination of fetal microglia increase the number of neural precursor cells in the developing cerebral cortex. Together, these data demonstrate that microglia play a key role in cortical development under normal and pathological conditions by regulating the size of the neural precursor cell pool.

\section{Materials and Methods}

Animal procedures, tissue processing, imaging. All animal procedures ( $n=$ 42 rats) were approved by the University of California, Davis Institutional Animal Care and Use Committee. Fixed macaque brain tissue obtained from fetuses of either gender $(n=5)$ was a gift from Dr. David Amaral (UC Davis MIND Institute, Sacramento, CA). Fixed prenatal human brain tissue was the gift from Dr. Jimenez-Amaya (Universidad 
Table 1. Cell count analysis and statistics in the embryonic cerebral cortex

\begin{tabular}{lllllll}
\hline & Group & Value & Animals & ANOVA & $\begin{array}{l}\text { Tukey- } \\
\text { Kramer }\end{array}$ & Cells \\
\hline iN0S/Iba1 & Control & $17.3 \pm 1.7 \%$ & 3 & $p=0.003$ & & 159 \\
& LPS & $28.2 \pm 2.6 \%$ & 4 & & $p<0.05$ & 216 \\
& Dox & $13.9 \pm 2.3 \%$ & 3 & & & 120 \\
IL-1 $\beta$ /lba1 & Control & $22.7 \pm 3.7 \%$ & 3 & $p=0.0009$ & & 281 \\
& LPS & $40.6 \pm 1.6 \%$ & 3 & & $p<0.01$ & 243 \\
& Dox & $15.2 \pm 1.3 \%$ & 3 & & & 293 \\
Arg-1/Iba1 & Control & $19.2 \pm 3.0 \%$ & 3 & $p=0.02$ & & 344 \\
& LPS & $20.6 \pm 1.4 \%$ & 3 & & & 321 \\
& Dox & $32.4 \pm 2.9 \%$ & 3 & & $p<0.05$ & 393 \\
IL-1RA/lba1 & Control & $14.0 \pm 3.3 \%$ & 3 & $p=0.02$ & & 287 \\
& LPS & $35.2 \pm 3.6 \%$ & 3 & & $p<0.05$ & 245 \\
& Dox & $27.5 \pm 4.3 \%$ & 3 & & & 312 \\
Pax6 & Control & $360.2 \pm 19.8$ & 6 & $p=0.002$ & & 2161 \\
& LPS & $264.4 \pm 26.8$ & 5 & & $p<0.05$ & 1320 \\
& Dox & $438.0 \pm 19.9$ & 3 & & $p<0.01$ & 1314 \\
Tbr2 & Control & $480.0 \pm 16.1$ & 6 & $p=0.0001$ & & 2880 \\
& LPS & $389.0 \pm 15.1$ & 5 & & $p<0.01$ & 1945 \\
& Dox & $585.3 \pm 7.8$ & 3 & & $p<0.01$ & 1755 \\
VZ/isVZ width & Control & $175.0 \pm 4.3$ & 6 & $p=0.0002$ & & 6 sections \\
& LPS & $138.0 \pm 4.9$ & 5 & & $p<0.001$ & 5 sections \\
& Dox & $186.6 \pm 8.8$ & 3 & & & 3 sections \\
CC3 & Control & $8.7 \pm 0.7$ & 3 & $p=0.07$ & & 26 \\
& LPS & $11.0 \pm 0.7$ & 4 & & & 44 \\
& Dox & $9.0 \pm 0.6$ & 3 & & & 27 \\
\hline & & & & & &
\end{tabular}

Autónoma de Madrid, Madrid, Spain). Timed pregnant rats were given single injections (IP) with $100 \mu \mathrm{g} / \mathrm{kg}$ lipopolysaccharide (LPS; E. coli 0111:B4, Sigma) on E15 and E16. Embryonic and postnatal rats of either sex were transcardially perfused and brains processed as previously described (Martínez-Cerdeño et al., 2012). Immunohistochemistry was performed as previously described (Martínez-Cerdeño et al., 2012). Primary antibodies were as follows: mouse anti-Pax6 (1:50, Abcam), NeuN (1:200, Millipore), inducible nitric oxide synthase (iNOS; 1:40, R\&D Systems), PCNA (1:50, Millipore), HLADR (1:50, BD Biosciences), phosphatidylserine (1:100, Millipore), and CD14 (1:50, BD Biosciences); rabbit anti-Pax6 (1:100, Covance), Tbr2 (1: 500, Abcam), Ibal (1:500, Wako), IL-1RA (1:100, Abcam), and Cleaved Caspase 3 (1:100, Cell Signaling Technology); goat anti-Iba 1 (1:100, Abcam), arginase-1 (1:20, Santa Cruz Biotechnology); chicken anti-Tbr2 (1:100, Millipore); rat anti-CD11b (1:20, BD Biosciences), IL-1 $\beta$ (1:50, R\&D), and F4/80 (1:50, EBiosciences). Secondary antibodies were conjugated to Dylight 405, Cy2/Dylight 488 , Cy3/Dylight 549, or Cy5/Dylight 649 (Jackson ImmunoResearch) and included donkey anti-mouse, donkey anti-rabbit, donkey antichicken, donkey anti-goat, and donkey anti-rat (1:200). Imaging was performed on an Olympus FV1000 confocal microscope. Analysis of Z-stack images through the entire extent of Iba1+ cells confirmed phagocytosis of precursor cells. Figures show single optical planes or projections from sequential confocal planes.

Ibal and precursor cell analysis. Sections of macaque occipital cortex were immunostained for Pax6, Tbr2, and cleaved caspase 3 (CC3). The proportion of precursor cells that were targeted or in the process of being phagocytosed by Iba1 + cells relative to total precursor cells was quantified in 300- $\mu \mathrm{m}$-wide bins that spanned from the ventricular surface through the outer subventricular zone (oSVZ) in macaque occipital cortex. All CC3 + cells in the germinal zones were imaged and the proportions of CC $3+$ cells that were Pax6 + or Tbr2+ were determined. InStat (GraphPad) was used to compare groups with ANOVA and TukeyKramer multiple-comparison post-tests to determine significance between experimental and control groups (Tables 1,2).

Time-lapse imaging of neocortical microglia. Neural precursor cells in E19 rat embryos were labeled through in utero intracerebral electroporation with a reporter gene expressing plasmid (pCAG-DsRed). One microliter of plasmid was injected into the lateral ventricle of E19 embryos
Table 2. Cell count analysis and statistics in the postnatal cerebral cortex

\begin{tabular}{lllllll}
\hline & Group & Value & Animals & ANOVA & Tukey-Kramer & Cells \\
\hline Pax6 & Control & $170.7 \pm 10.1$ & 3 & & & 512 \\
& LPS & $136.7 \pm 11.4$ & 3 & & & 410 \\
& Dox & $258.7 \pm 13.0$ & 3 & $p=0.0008$ & $p<0.01$ & 776 \\
Tbr2 & Control & $181.7 \pm 18.7$ & 3 & $p=0.0006$ & & 545 \\
& LPS & $144.7 \pm 5.2$ & 3 & & $p<0.05$ & 434 \\
& Dox & $283.7 \pm 10.0$ & 3 & & $p<0.01$ & 852 \\
\multirow{4}{*}{ VZ/isVZ width } & Control & $106.7 \pm 6.7$ & 3 & $p=0.0002$ & & 3 sections \\
& LPS & $86.7 \pm 3.3$ & 3 & & & 3 sections \\
& Dox & $166.7 \pm 6.7$ & 3 & & $p<0.001$ & 3 sections \\
CC3 & Control & $44.7 \pm 4.6$ & 3 & $p=0.05$ & & 134 \\
& LPS & $36.0 \pm 4.0$ & 3 & & & 108 \\
& Dox & $27.3 \pm 1.9$ & 3 & & $p<0.05$ & 82 \\
\multirow{4}{*}{ NeuN } & Control & $23.0 \pm 6.4$ & 3 & $p=0.0001$ & & 69 \\
& LPS & $20.3 \pm 3.9$ & 3 & & & 61 \\
& Dox & $137.3 \pm 6.2$ & 3 & & $p<0.001$ & 412 \\
\hline
\end{tabular}

followed by electroporation ( 5 pulses, $50 \mathrm{~V}, 50 \mathrm{~ms}$ pulse length, $1 \mathrm{~s}$ interpulse interval; BTX). One day later embryos were killed, and the live cerebrum was sectioned at $300 \mu \mathrm{m}$ on a vibratome and the sections were placed in bubbling carbogenated aCSF until all brains were cut. Sections were transferred to six-well plates with Millicell culture inserts (Millipore) and slice culture media containing (v/v): 66\% BME, 25\% HBSS, $5 \%$ Fetal Bovine Serum, 1\% N-2 Supplement, 1\% Pen/Strep/Glutamine (Invitrogen) and (w/v) $0.66 \% \mathrm{D}+$ Glucose (Sigma). Slices were maintained in a humidified, $37^{\circ} \mathrm{C}$ incubator containing ambient oxygen and $5 \% \mathrm{CO}_{2}$. Six-well plates containing slices were removed from the incubator and cells were imaged on an Olympus FV1000 confocal microscope at 15-30 min intervals for up to $36 \mathrm{~h}$. Twenty-four hours after electroporation $>95 \%$ of DsRed-expressing cells in the VZ and SVZ were positive for either Pax6 or Tbr2. Microglia were labeled by bathing slices for $1 \mathrm{~h}$ in Isolectin B4 (IB4) from Griffonia simplicifolia conjugated to Alexa Fluor 488 (5 $\mu \mathrm{g} / \mathrm{ml}$, Life Technologies/Invitrogen) (Dailey et al., 2011). Time-lapse images of labeled microglia and precursor cells in the rat VZ/SVZ were recorded on an Olympus laser-scanning confocal microscope and images were assembled for analysis with Adobe Photoshop as described previously (Noctor, 2011).

Pharmacological treatments and analysis. Microglial activation was suppressed in vitro with minocycline (100 $\mu \mathrm{M}$, Sigma) and in vivo with doxycycline $(200 \mathrm{mg} / \mathrm{kg}$ in food pellet chow, Bioserv). For in vitro microglial suppression, organotypic slice cultures were prepared from E16 rats as described above. Slices were subjected to treatment with $0.1 \mathrm{M}$ PBS or $100 \mu \mathrm{M}$ Minocycline (Sigma) for $3 \mathrm{~d}$ in vitro. Slices were fixed for $1 \mathrm{~h}$ at room temperature in $4 \%$ paraformaldehyde (PFA), followed by immunostaining and analysis. Microglial activation was suppressed in vivo with doxycycline (200 mg/kg in food pellet chow, Bioserv), given ad libitum starting at E15. Food was weighed daily. To augment microglial activation in vivo we modeled maternal immune activation by treating timed pregnant rats with single injections of LPS (100 $\mu \mathrm{g} / \mathrm{kg}$ IP, Sigma) on gestation days E15 and E16. Analyses in rodent (E16, E19, P2, P4, or P10) were performed in coronal sections at the level of the anterior commissure. The proportion of microglia that were arginase- $1+$, iNOS + , IL$1 \beta+$, or IL-1RA + were quantified in a $600-\mu \mathrm{m}$-wide bin that stretched from the ventricle through the cortical plate. The total number of Pax6+ and/or Tbr $2+$ cells was quantified in a $200-\mu \mathrm{m}$-wide bin that stretched from the ventricular surface to the cortical plate. The number of NeuN+ cells was quantified in a $300 \times 300 \mu \mathrm{m}$ bin in the oSVZ in dorsomedial cortex. The total number of CC3 + nuclei per hemisphere was quantified.

Selective depletion of microglia with liposomal clodronate. Liposomes containing PBS or clodronate (Encapsula Nanosciences) were prepared as described previously. For in vitro experiments, organotypic slice cultures were prepared from E20 rats as described above. Slices were treated for $24 \mathrm{~h}$ with tissue culture media containing $0.1 \mathrm{M} \mathrm{PBS}$, liposomes containing PBS at a 1:5 dilution, or liposomes containing clodronate at a 1:5 dilution. After treatment, slices were washed with tissue culture media and allowed to incubate for 48 additional hours at $37^{\circ} \mathrm{C}$. For in vivo 


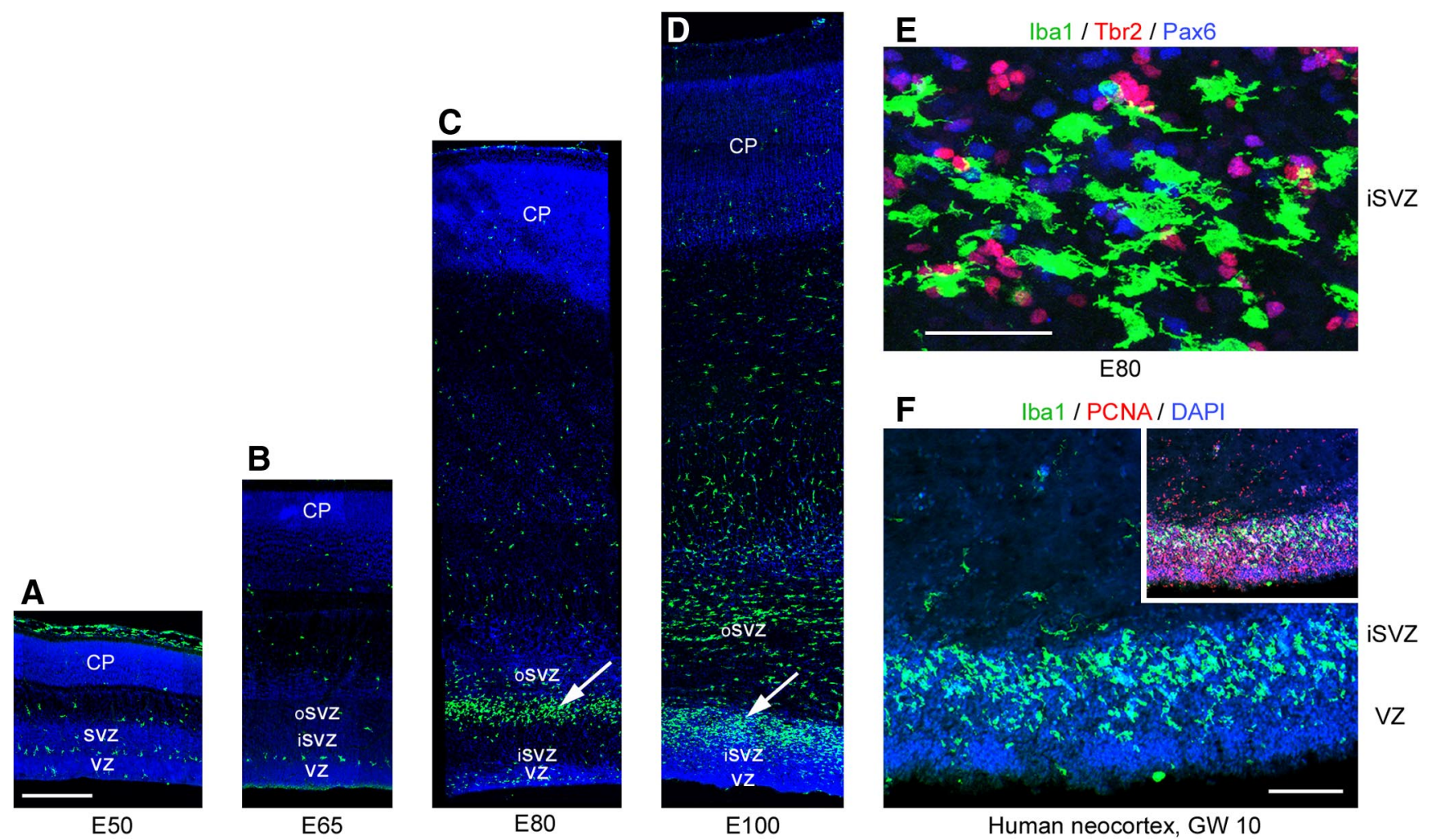

Figure 1. Iba1+ microglia colonize the proliferative zones of the developing primate forebrain. $A, B$, There are relatively few lba + cells (green) in the developing macaque occipital cortex during early stages of neurogenesis (E50 and E65). A monolayer of lba $1+$ cells is visible at the interface between the VZ and SVZ and between the SVZ and IZ, DAPI (blue). C, By E80 activated Iba1 + cells (green) colonize the SVZ at the interface between the inner fiber layer and the OSVZ (white arrow), DAPI (blue). D, AtE100 there is a dense band of Iba1+ cells in the iSVZ (white arrow) and numerous Iba1 + cells in the 0SVZ, DAPI (blue).E, Iba1+ cells (green) in the E80SVZare closely associated with Pax6 + (blue) and Tbr2 + (red) precursor cells.F,A dense band of lba1+ cells (green) colonizes the iSVZ of the human neocortex by 10GW, DAPI (blue). The inset shows Iba1+ cells (green) are closely associated with proliferative PCNA + precursor cells (red). Scale bars: $A-D, 500 \mu \mathrm{m} ; \boldsymbol{E}, 50 \mu \mathrm{m} ; \boldsymbol{F}, 100 \mu \mathrm{m}$.

experiments, pregnant rats were anesthetized at E16 or E20, a laparotomy was performed, and the uterine horns were removed. Liposomes were warmed to room temperature and $2-3 \mu$ l were injected into the lateral ventricles using glass micropipettes. The uterus was replaced, the incision sutured, and the pregnant animal allowed to recover. One to three days after injection, embryos at $\mathrm{E} 17$ or pups at $\mathrm{P} 1$ were transcardially perfused with $4 \%$ PFA, coronally sectioned, and immunostained. At E17, the number of Iba1 + microglia and Tbr2 + intermediate progenitor cells were quantified in 200- $\mu \mathrm{m}$-wide bins that stretched from the ventricle to the pial surface. At P1, the number of Iba1+ microglia, Pax6+ precursor cells, and Tbr $2+$ intermediate progenitor cells were quantified in a $300 \times$ $300 \mu \mathrm{m}$ bin in the oSVZ of dorsomedial cortex.

\section{Results}

\section{Microglia colonize cortical proliferative zones}

We analyzed the temporal and regional distribution of microglia in the occipital neocortex of the rhesus monkey (Macaca mulatta) with antibodies against ionized calcium binding adapter molecule 1 (Iba1), which labels resting and activated microglia (Imai et al., 1996; Morgan et al., 2010). Iba1 + cells sparsely populated the cerebral cortex at embryonic day 50 (E50), when cortical layer 6 neurons are generated (Rakic, 1974). Interestingly, we noted a monolayer of Iba1+ cells at the interface between the VZ and SVZ (Fig. 1A). At E50 many Iba1 + cells were located near blood vessels, a location shared by Tbr $2+$ neural precursor cells in rodents (Javaherian and Kriegstein, 2009; Stubbs et al., 2009). At E65, when cortical layer 5 and 6 neurons are generated (Rakic, 1974), the distribution of Iba1+ cells in the macaque cerebral cortex was still relatively sparse (Fig. $1 \mathrm{~B}$ ). However, by E80 during production of layer 4 neurons (Rakic, 1974), a dense band of Iba1+ cells had selectively colonized the SVZ
(Fig. 1C). By E100, at the end of macaque cortical neurogenesis (Rakic, 1974), dense bands of Iba1 + cells populated the inner SVZ (iSVZ) and outer SVZ (oSVZ, Fig. 1D). The position of the Iba1+ cells in the primate SVZ corresponded to the location of Pax6 + and Tbr2 + neural precursor cells (Fig. 1E), which are distributed throughout the iSVZ and oSVZ during cortical neurogenesis (Fietz et al., 2010; Hansen et al., 2010; Martínez-Cerdeño et al., 2012). We tested whether the selective colonization of the SVZ was specific to macaque by staining human fetal and developing rodent neocortex with Ibal antibodies. Human neocortex at 10 weeks of gestation displayed a similar colonization of the SVZ and colocalization of Iba1 + cells with proliferative precursor cells (Fig. $1 F$ ). The temporal distribution of Iba1 + cells in the rat neocortex followed a similar trend to that of macaque. Iba1 + microglia were sparsely distributed throughout the rat cortex at E13 and E17 (Fig. 2A,B), as in the macaque at E50 and E65. By E19, during the peak of layer 2 neurogenesis in rat (Bayer and Altman, 1991), Iba1 + microglia had colonized the VZ and SVZ (Fig. 2C). One day later at E20 the number of Iba1+ microglia in the VZ and iSVZ had increased substantially (Fig. 2D). The increased number of Iba1+ microglia in the rat proliferative zones coincided temporally with the thinning of the proliferative layers (Bayer and Altman, 1991). Some Iba1+ cells in the rat VZ evoked radial glial morphology. These microglial cells had a bipolar morphology with a soma in the VZ, a single process that extended toward the ventricle and a short process that ascended to the top of the VZ, but lacked the pial process characteristic of radial glial cells (Fig. $2 E-H$, arrowheads). We also observed Iba1 + cells at the ventricular surface in rat and macaque. Many of these cells did not have visible processes (Fig. 2 J), but often appeared to be migrating tan- 

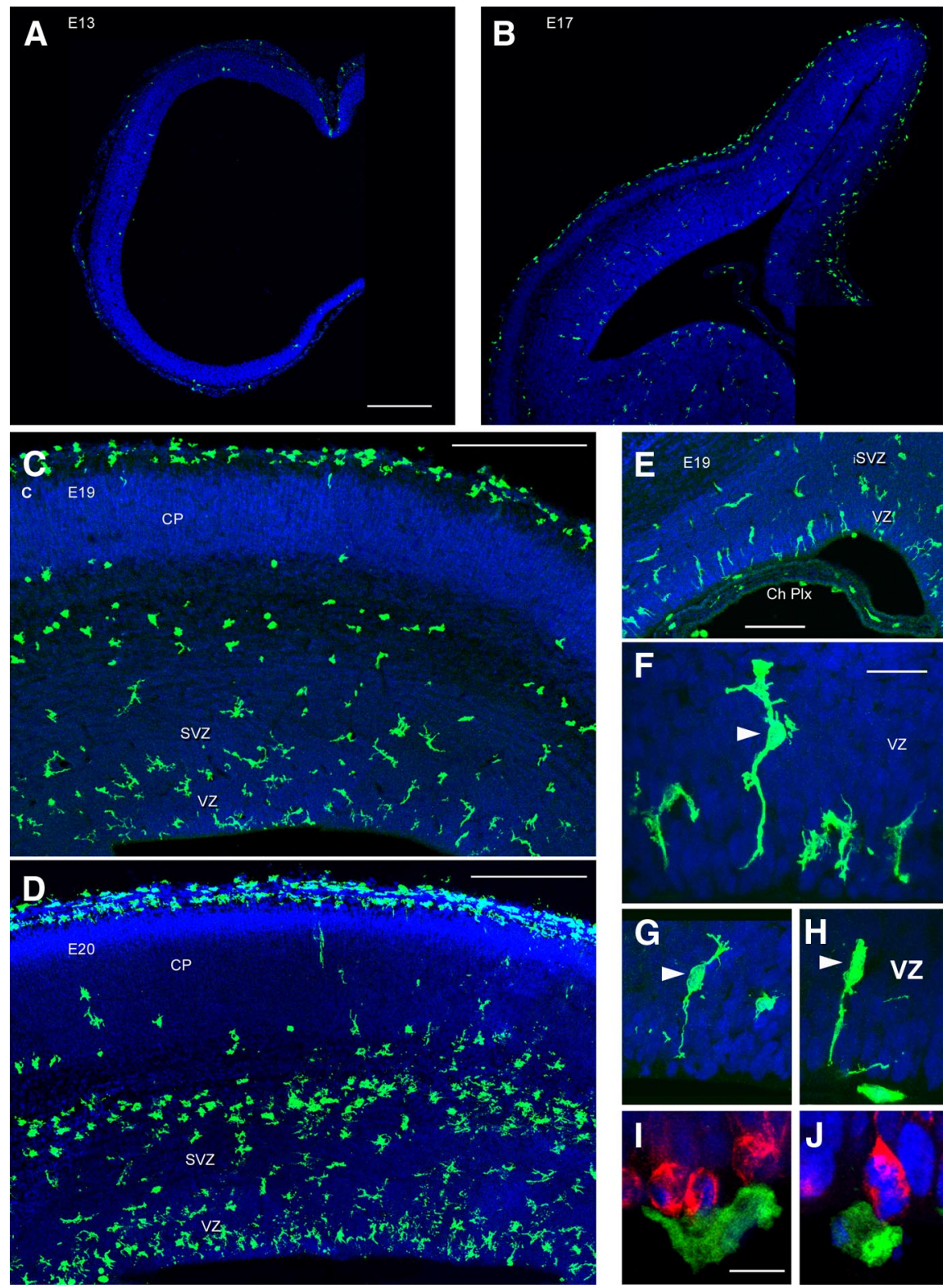

Figure 2. Iba1+ microglia colonize the rat proliferative zones. $A$, At E13 very few Iba $1+$ microglia (green) are present in the telencephalic wall. $\boldsymbol{B}$, At E17 Iba1 + cells (green) are distributed sparsely throughout the neocortex. A small number are visible in the proliferative zones. AtE17 and later ages Iba1 + cells densely populate the marginal zone and pia. C, By E19 increased numbers of lba $1+$ cells (green) were present in the cortical VZ and SVZ. Iba 1 + cells were virtually absent from the embryonic cortical plate. D, By E2O a dense band of Iba $1+$ cells (green) was present in the rodent VZ and iSVZ, and a second band of amoeboid-shaped Iba1 + cells was present at the interface between the 0 SVZ and IZ.E, Iba1 + cells (green) were also present throughout the choroid plexus (Ch Plx). Some lba1 + microglia in the VZ evoked radial glial morphology but lacked a pial process. $\boldsymbol{F}-\boldsymbol{H}$, The RG-like lba1+ cells were bipolar with somata in the VZ (white arrowheads), a single process that appeared to contact the ventricle, and a short process that ascended to the top of the VZ. These cells lacked the pial process characteristic of radial glial cells. I, lba1 + cells (green) were also present along the surface of the ventricle in close contact with mitotic 4A4+ VZ precursor cells (red). J, Many of these cells had a rounded morphology and lacked processes, but did not stain positive for mitotic markers such as PH3. A-J, DAPI (blue). Scale bars: $A-D, 250 \mu \mathrm{m} ; \boldsymbol{E}, 100 \mu \mathrm{m} ; \boldsymbol{F}-\boldsymbol{H}, 20 \mu \mathrm{m} ; \boldsymbol{I}, \boldsymbol{J}, 10 \mu \mathrm{m}$.

gentially along the apical surface of mitotic VZ cells (Fig. 2I,J). We found that mitotic microglia did not stain positive for the mitotic cell marker phosphorylated vimentin (4A4), but did stain positive for phosphohistone $\mathrm{H} 3$ ( $\mathrm{PH} 3)$. We did not observe mitotic $\mathrm{PH} 3+$ microglia at the surface of the ventricle in rat or macaque. Some features of the distribution of Ibal + cells were shared in human, macaque, and rat developing neocortex. For example, there were relatively few Ibal + cells in the cortical plate of each species during neurogenic stages. But there were also notable differences. The VZ persists as a

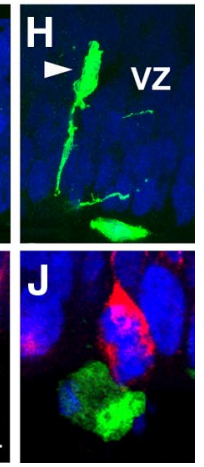

prominent zone throughout neurogenesis in rat and the majority of Pax6 + neural precursor cells remain in the VZ throughout rodent neurogenesis (Martínez-Cerdeño et al., 2012). In contrast, the macaque VZ becomes considerably thinner during early stages of neurogenesis (Smart et al., 2002) and the majority of Pax6+ neural precursor cells shift to the oSVZ (Martínez-Cerdeño et al., 2012). Similarly, we found that Iba1+ cells densely populated the rat VZ throughout neurogenesis (Fig. 2), whereas in macaque the majority of Ibal+ cells were located in the SVZ throughout cortical neurogenesis (Fig. 1). We also noted that the density and position of $\mathrm{Ibal}+$ bands within the macaque SVZ varied markedly in neighboring cortical areas of the occipital lobe (Fig. 3), but did not differ as drastically across cortical areas in the rat.

The morphology of Iba1 + cells in the neocortex of each species ranged from ramified cells that appeared to be resting microglia, to cells that had the characteristic appearance of activated microglia, which is correlated with proliferation and phagocytosis (Rezaie and Male, 1999). Greater than $95 \%$ of Iba1+ cells in the proliferative zones had the morphology of activated microglia, with large somata up to $30 \mu \mathrm{m}$ in diameter, a few thick processes and large lamellipodia that extended toward the surrounding cells (Fig. $4 A)$. Microglia in the oSVZ and in some developing white matter tracks in the prenatal rat neocortex often exhibited a rounded "amoeboid" morphology (Fig. 2), as noted in previous studies (Ashwell, 1991). In comparison, relatively few microglia exhibited an amoeboid morphology in the prenatal macaque neocortex. Colabeling with markers of activated microglia such as CD14, F4/80 (Alliot et al., 1999), CD11b (Biscaro et al., 2012; d'Avila et al., 2012), MHCII/HLADR (Monier et al., 2007), and iNOS (Verney et al., 2010) confirmed that Ibal + cells in the neocortex were microglia and that nearly all $\mathrm{Iba} 1+$ cells in the proliferative zones expressed markers of activated microglia (Fig. 4B). After cortical neurogenesis (E150 in the macaque, $\mathrm{P} 13$ in rat), Iba1 + microglia were no longer concentrated in the proliferative zones but instead were distributed evenly throughout the cortex (Fig. 5).

\section{Microglia phagocytose neural precursor cells in the primate SVZ}

Previous work has shown that microglia appear in the cortical proliferative zones during early stages of development (Ashwell, 1991; Alliot et al., 1999; Rezaie and Male, 1999; Swinnen et al., 2012), where they might propagate and seed the cortex with additional microglial cells (Rezaie and Male, 1999). Consistent with this view, we found that many Iba1 + microglia in the proliferative zones ex- 


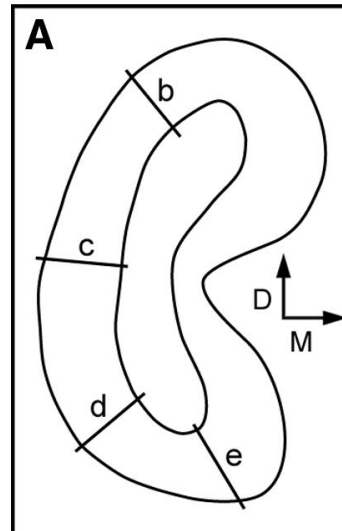

\section{E80 macaque}

occipital cortex,

single section

E

D

B

C
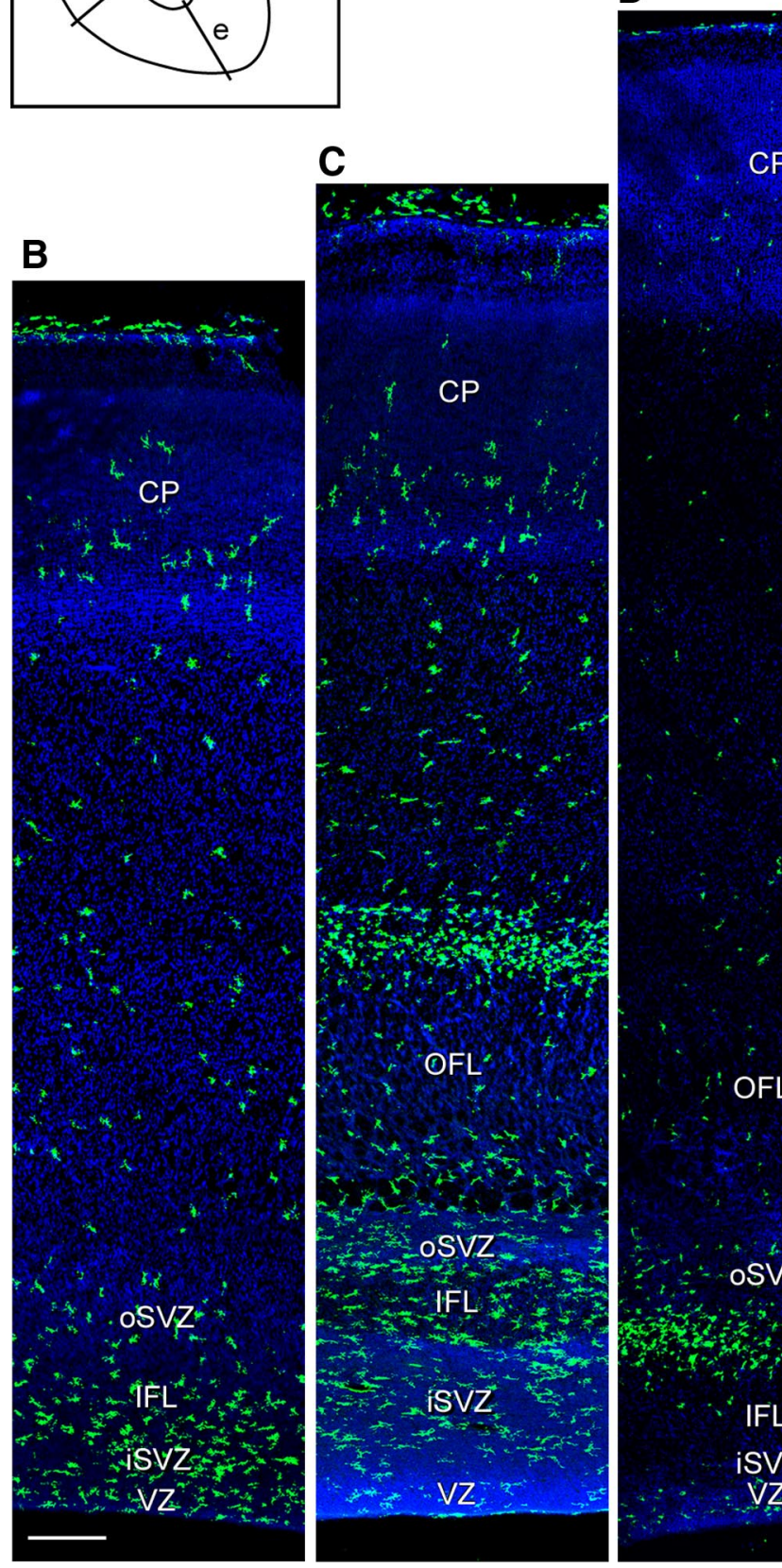

$\mathrm{CP}$
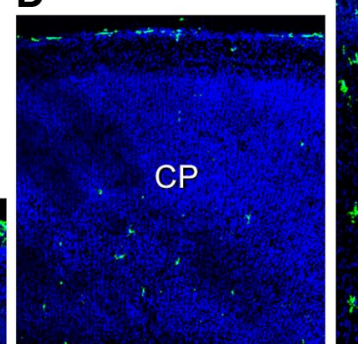

$\because \mathrm{OFL}$
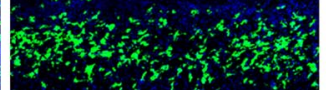

IFL

iSVZ

YZ

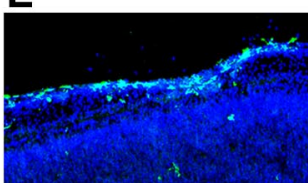

CP
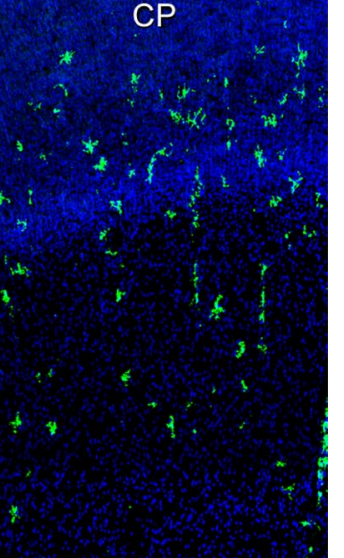

Figure 3. Iba1+ microglia distribution varies across cortical areas. $A$, Line drawing of a single coronal section of E80 macaque occipital cortex that was stained for Iba1 and confocal imaged to produce the images shown in $\boldsymbol{B}-\boldsymbol{E}$. Location of panels indicated by labeled lines, and orientation is indicated with arrows. $\boldsymbol{B}-\boldsymbol{E}$, Iba1 + microglia (green) colonize the iSVZ and oSVZ in the occipital cortex, but the position of the dense lba $1+$ cell bands varies across cortical areas. Scale bar: (in $\boldsymbol{B}) \boldsymbol{B}-\boldsymbol{E}, 250 \mu \mathrm{m}$. Blue, DAPI. 
A

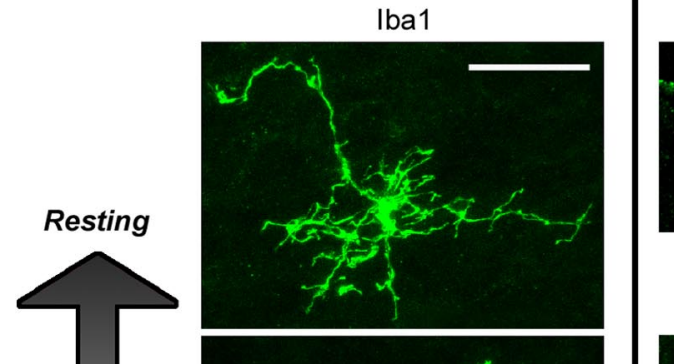

lba1

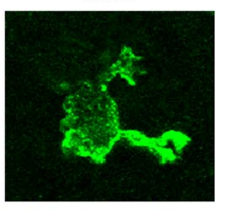

Iba1

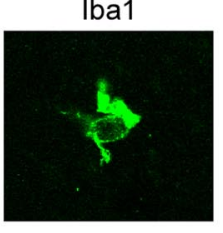

Iba1

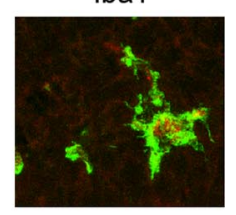

Iba1

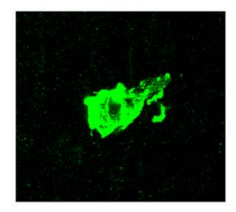

Iba1

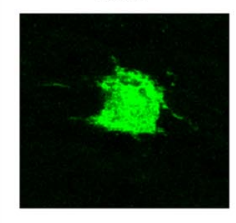

CD14

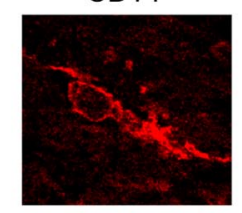

F4/80

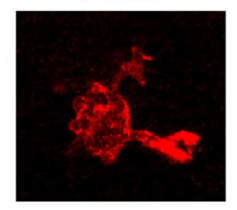

F4/80

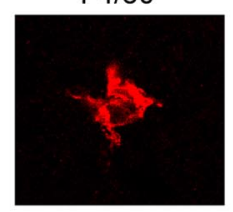

CD11b

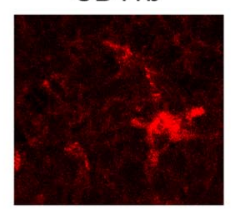

HLADR

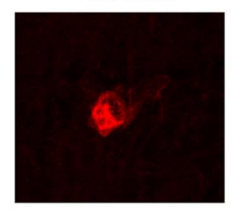

iNOS

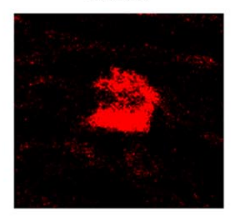

merge

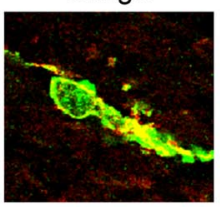

merge

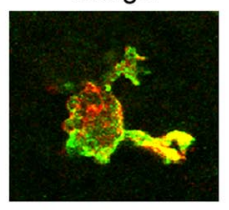

merge

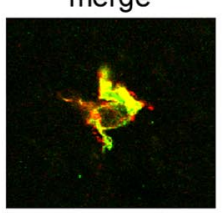

merge

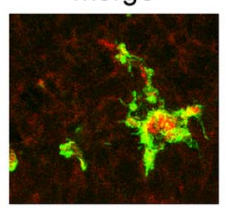

merge

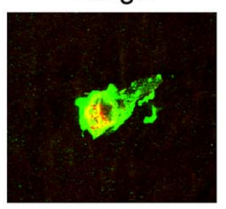

merge

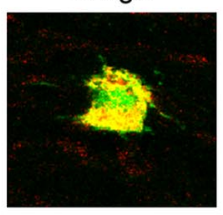

C

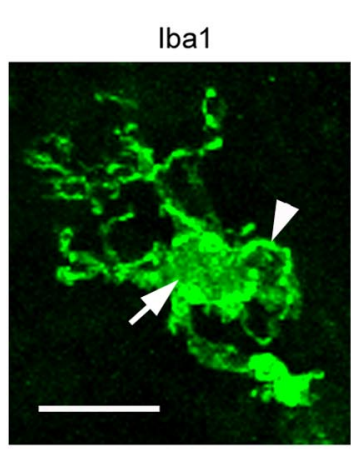

PCNA

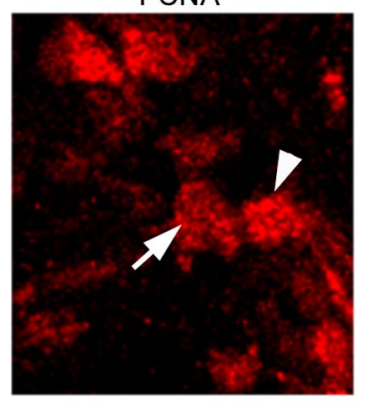

DAPI

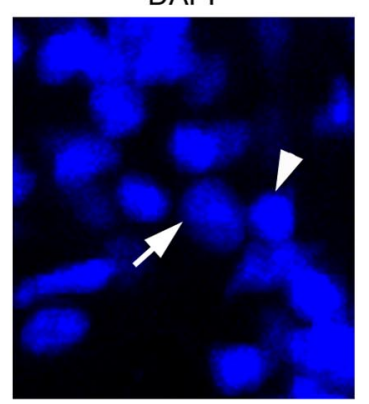

merge

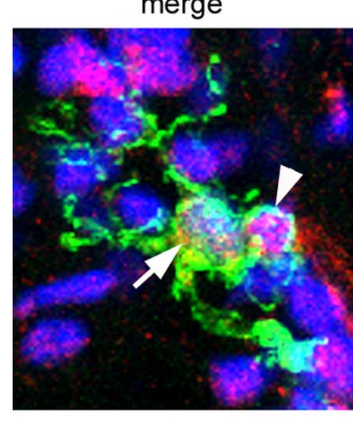

Figure 4. Iba1+ cells in the prenatal neocortex are microglia. $\boldsymbol{A}$, The morphology of $\mathrm{lba} 1+$ cells in the E80 macaque neocortex ranged from cells with a small soma and fine ramified processes that appeared to be in a resting state, to cells with an activated morphology-a large soma with a few thick processes (Rezaie and Male, 1999). The overwhelming majority of Iba1+ cells in the E50 -E100 macaque neocortex and the E13-P4 rodent neocortex had an activated morphology. B, Iba1+ cells (green) coexpressed traditional markers of activated microglia including CD14, F4/80, CD11b, HLADR, and iNOS (red). C, Most lba1 + cells (green) in the prenatal brain expressed the mitotic marker PCNA (red). The nucleus of this lba1 + cell is indicated with a white arrow, the PCNA + cell being phagocytosed is indicated with a white arrowhead. Blue, DAPI. Scale bars: $A, C, 20 \mu \mathrm{m} ; \boldsymbol{B}, 10 \mu \mathrm{m}$.

pressed the proliferative marker PCNA (Fig. 4C), and we noted increased numbers of microglia in the cerebral cortex at each stage of development. However, there were very few M-phase microglia in the proliferative zones. Furthermore, we noted that microglia selectively colonized the cortical proliferative zones (See Fig. 1E), which are densely populated by Pax6 and Tbr2-expressing neural precur- sor cells (Englund et al., 2005; Fietz et al., 2010; Hansen et al., 2010; Martínez-Cerdeño et al., 2012). We therefore examined the relationship between microglia and neural precursor cells in the macaque SVZ throughout neurogenic (E50, E65, E80, and E100) and postneurogenic (E109 and E123) stages of cortical development. We found that microglia contacted, engulfed, and phagocytosed Tbr2+ 
and Pax6 + cells in the SVZ at all stages of development (Fig. 6A-J). Confocal imaging confirmed that Tbr2+ and Pax6+ nuclei were located within the somata of Iba1 + microglia. Some Iba1 + microglia contained full sized Pax6+ or Tbr2+ nuclei (Fig. 6F), but others contained Pax6+ or Tbr2+ puncta (Fig. $6 G, H$ ), suggesting degradation of the precursor cells after phagocytosis. While microglial cells were concentrated in distinct bands in the SVZ, microglial targeting of precursor cells was not restricted to the Iba1 + cell bands but occurred throughout the macaque iSVZ and oSVZ. We quantified the proportion of Tbr2+ cells that were contacted or in various stages of engulfment by Iba1 + microglia in 300- $\mu$ mwide bins that spanned radially through the proliferative zones. At E50 only 2.1\% of Tbr2 + cells (17/797), and at E65 3.5\% of Tbr2 + cells $(46 / 1310)$ were targeted by Iba1 + microglia. However, the proportion of Tbr2+ cells targeted by microglia increased significantly at later stages: $16.5 \%$ of Tbr2 + cells $(227 / 1374)$ at E80, and $34.7 \%$ of Tbr 2 c cells $(251 / 722)$ at E100 were targeted by microglia (Fig. 7).

To determine whether microglia that contacted Tbr2+ or Pax6+ cells in the neural proliferative zones would ultimately phagocytose those cells, we recorded the behavior of microglial cells in the cortical proliferative zones in live organotypic slice cultures prepared from the embryonic cerebral cortex of rats. Neural precursor cells were labeled by in utero intracerebral electroporations in E19 rat embryos with a reporter gene expressing plasmid (pCAG-DsRed; MartínezCerdeño et al., 2012). Twenty-four hours later embryos were killed, the live cerebrum sectioned at $300 \mu \mathrm{m}$, and the slices maintained as organotypic slice cultures. We fixed and immunostained slices and found that $97 \%$ of DsRed + cells in the VZ and SVZ stained positive for Tbr2, Pax6, or both, indicating that the vast majority of DsRed + cells in the proliferative zones were precursor cells. Slices were bathed for $1 \mathrm{~h}$ in isolectin B4 conjugated to Alexa Fluor 488 to label microglia (Dailey et al., 2005). Time-lapse images of labeled microglia and precursor cells in the rat $\mathrm{VZ}$ were recorded from individual slices for up to $36 \mathrm{~h}$ as previously described (Noctor et al., 2001, 2002, 2004, 2008; Noctor, 2011; Martínez-Cerdeño et al., 2012). Microglia contacted precursor cells and in the majority of cases (68/75) microglia phagocytosed the cells 30 min to 10 h later (Fig. 8). The phagocytosed cells rapidly broke down into small fluorescent puncta within the microglia (Fig. 8) as we observed in vivo (Fig. 6), and often were no longer visible after $2 \mathrm{~h}$.
A E150 macaque

B

P13 rat
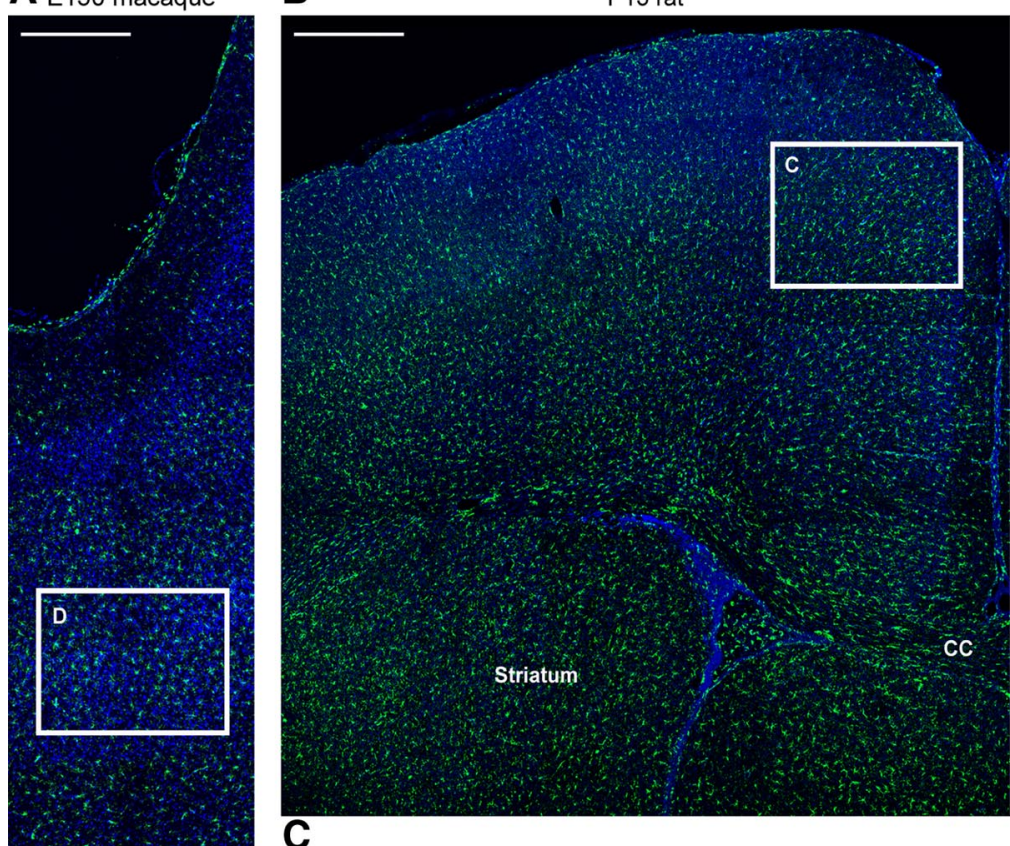

C

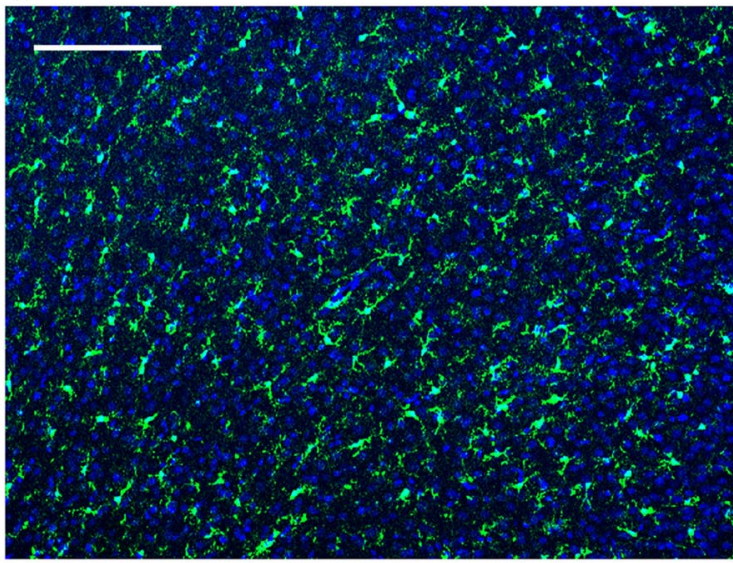

D

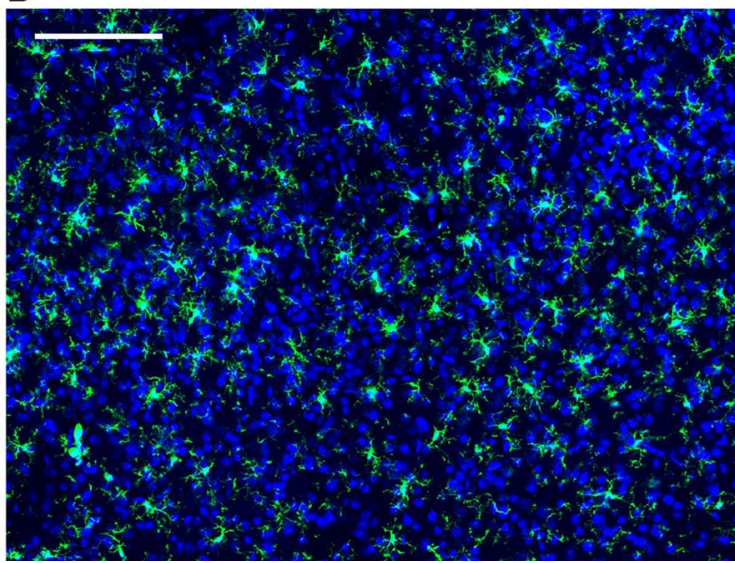

Figure 5. Microglia are distributed evenly across the entire cerebral cortex after neurogenesis. $A, D$, Coronal sections of E150 macaque occipital costained for Iba1 (green) and DAPI (blue). $\boldsymbol{B}, C$, Coronal sections of P13 rat cortex costained for Iba1 (green) and DAPI (blue). White inset boxes show location of higher magnification panels shown in $C, D$. In both species many of the microglia in the cortical gray matter exhibit an activated morphology. CC, Corpus callosum. Scale bars: $\boldsymbol{A}, \boldsymbol{B}, 500 \mu \mathrm{m} ; \boldsymbol{C}, \boldsymbol{D}, 150 \mu \mathrm{m}$.

One well described function performed by microglia is the removal of damaged, dead, and dying or apoptotic cells (Kettenmann et al., 2011). Previous reports have shown that manipulating apoptosis via caspase mutations in the embryonic brain can 

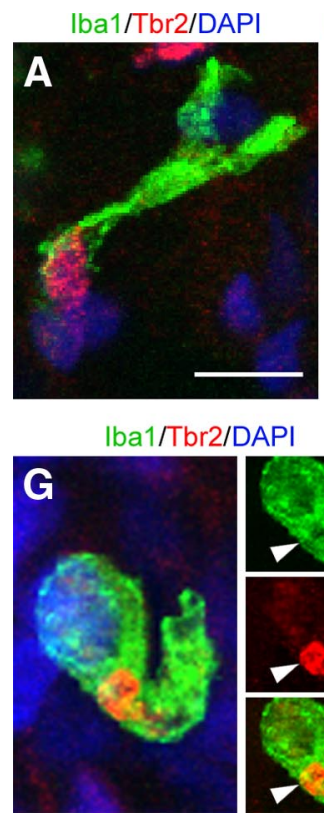
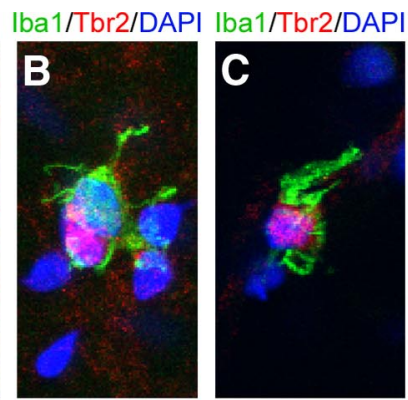

|ba1/Tbr2/DAPI
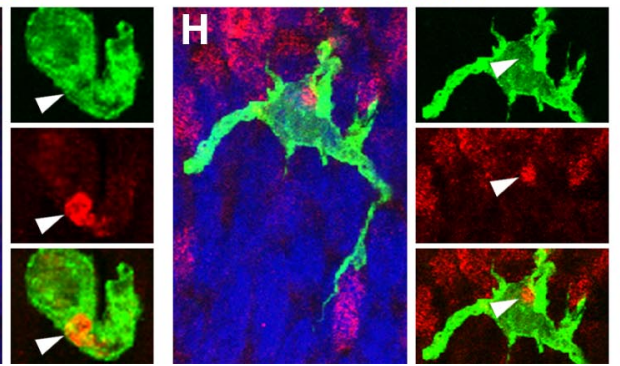

|ba1/Tbr2/DAP|

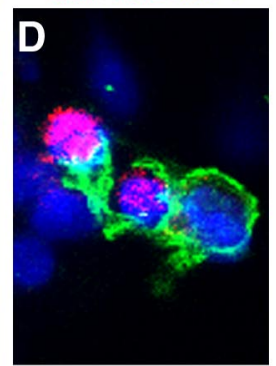

Iba1/PCNA/DAPI

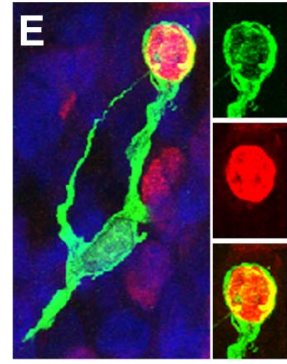

|ba1/Pax6/DAP|
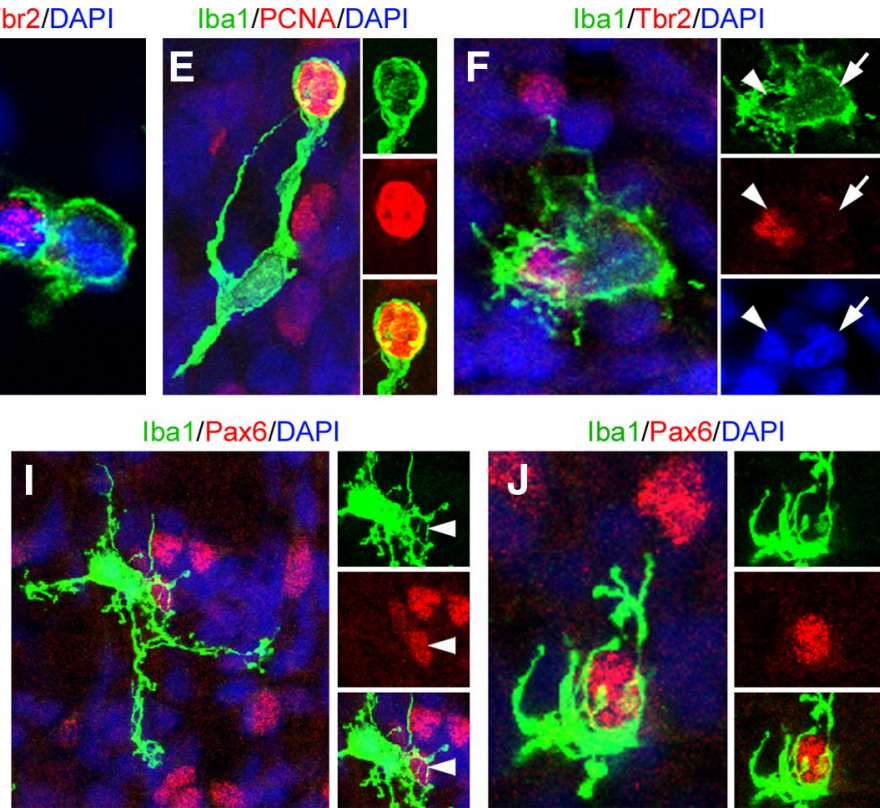

|ba1/Pax6/DAPI

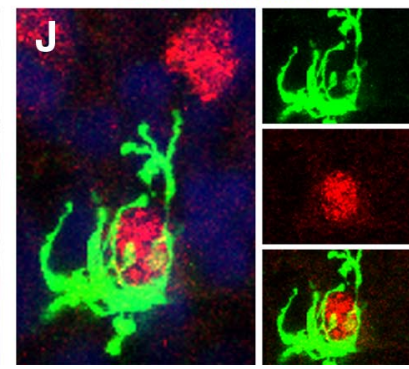

Figure 6. Iba1+ microglia phagocytose neural precursor cells in the developing neocortex. $\boldsymbol{A}-\boldsymbol{D}, \mathrm{lb}$ 1 $1+$ microglia (green) in the E80 macaque SVZ contact and envelope Tbr2 + neural precursor cells (red). $\boldsymbol{E}$, An lba1+ microglial cell (green) enveloping a PCNA-positive mitotic cell (red). $\boldsymbol{F}$, A Tbr2 + nucleus (red, white arrowhead) inside an Iba1+ microglial cell (green). The nucleus of the microglial cell (DAPI, blue) is indicated by a white arrow. G, H, Microglia (green) contained Tbr2 + (red) puncta indicating degradation after phagocytosis. I, J, Microglia (green) contact and envelope Pax6+ precursor cells (red). Panels show confocal optical plane images. Nuclei stained with DAPI (blue). Scale bar: (in $\boldsymbol{A}) \boldsymbol{A}-\boldsymbol{J}, 10 \mu \mathrm{m}$.

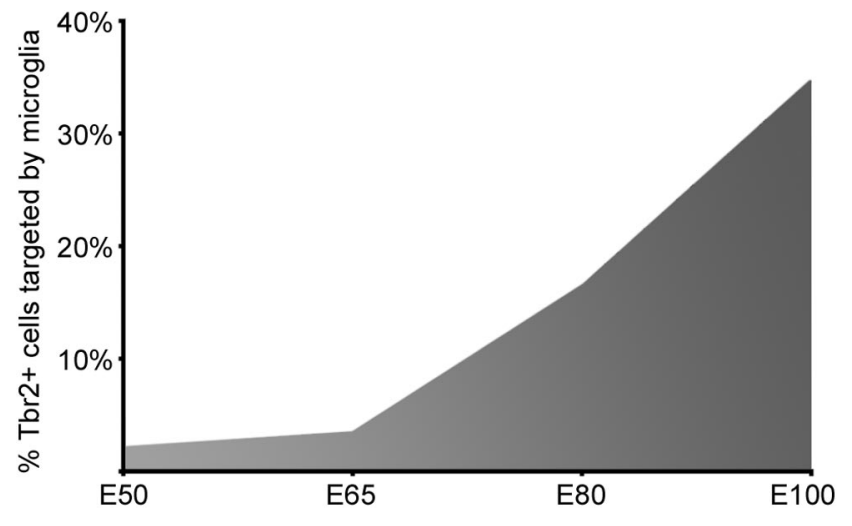

Figure 7. The proportion of Tbr2 + neural precursor cells targeted by lba1 + microglia increases during later stages of cortical neurogenesis. The proportion of all Tbr2 + cells in a $200-\mu \mathrm{m}$-wide bin that is targeted by lba1+ microglia is $\sim 2 \%$ at the start of neurogenesis (E50), 3\% during deep layer neurogenesis (E65), and rises to $>33 \%$ at the end of neurogenesis (E100).

alter the size of the precursor cell pool (Kuida et al., 1998). We therefore tested whether neural precursor cells in the prenatal cortex that were targeted by microglia exhibited hallmarks of cell death. We double immunostained tissue with anti-CC3, a marker of cells in early stages of apoptosis, and Tbr2, Pax6, or Iba1 antibodies. There were relatively few $\mathrm{CC} 3+$ cells in the proliferative zones of the E80 macaque occipital cortex, $\sim 75$ CC $3+$ cells per hemisphere. We observed a few microglial cells that targeted CC3 + cells (Fig. 9A), but the overwhelming majority of targeted Pax6+ and Tbr2+ precursor cells were CC3-negative (>99\%). We observed a similar number and distribution of TUNEL + cells in the developing neocortex, indicating that microglia were not primarily targeting CC3 + or TUNEL + cells in the cortical proliferative zones. Cells undergoing cell death can display "eat me" signals, such as expression of phosphatidylserine (PS) on the cell surface, which marks cells in early stages of cell death for clearance by microglia and macrophages (Savill and Fadok, 2000; Wu et al., 2006). We used anti-PS antibodies and found that PSexpressing cells were not concentrated in the proliferative zones where most microglia were located, but instead were distributed evenly across the cortical wall. Furthermore, many target precursor cells were PS-negative. We also found that most precursor cells targeted by microglia expressed high levels of PCNA, suggesting that target precursor cells were mitotically active (Fig. $9 B)$. Finally, DAPI staining showed that the vast majority of precursor cells targeted by Iba1 + microglia had normal chromatin staining, rather than the clumped, shrunken, or fragmented chromatin characteristic of dying cells. Together, these data show that most precursor cells targeted by Iba1 + microglia in the cortical proliferative zones did not show signs of cell death or apoptosis as defined by CC3, TUNEL, PS expression, or nuclear breakdown. Our findings are consistent with the concept that microglia can phagocytose viable cells independent of apoptotic pathways (Fricker et al., 2012).

Iba1 + microglia also targeted and phagocytosed NeuN+ neurons in the proliferative zones (Fig. 9C). Phagocytosis of neurons by microglia has been well documented (Kettenmann et al., 2011). Notably, we found that during prenatal cortical neurogenesis, phagocytosis of NeuN + neurons occurred primarily in the proliferative zones rather than in the cortical plate.

\section{Manipulating microglial activation alters the number of neural precursor cells}

Increased targeting of precursor cells by microglia coincided with the decline in the number of Tbr2 + cells in the macaque neural proliferative zones, which occurs after E80 (Martínez-Cerdeño et al., 2012). We therefore tested whether microglial cells regulate the size of the neural precursor pool through phagocytosis. We reasoned that if activated microglia phagocytose a significant proportion of neural precursor cells, then deactivating microglia 

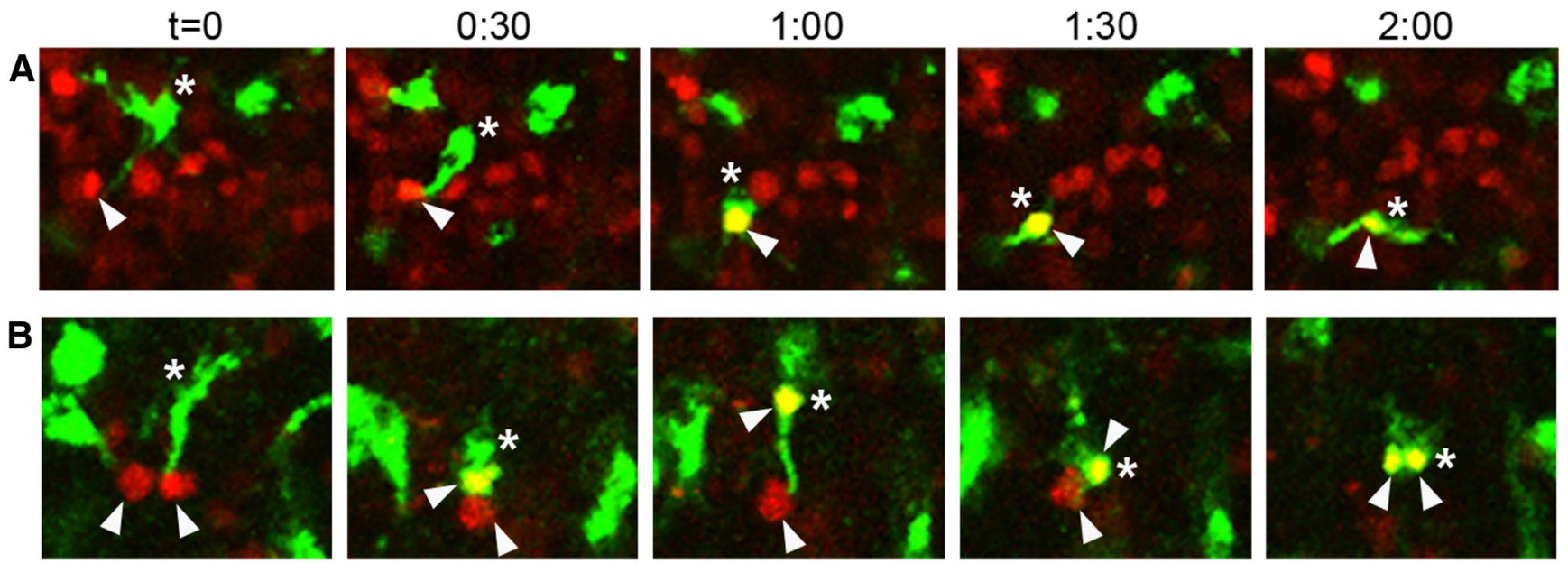

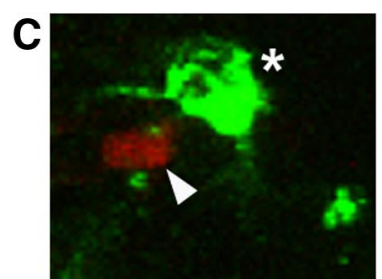

$\mathrm{t}=0$

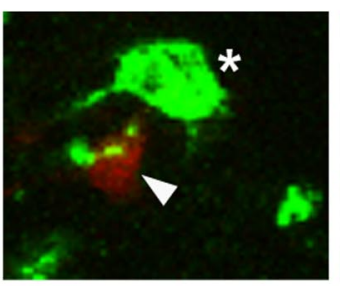

$0: 50$

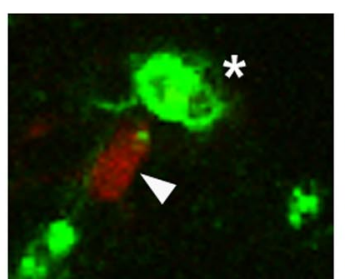

$1: 37$

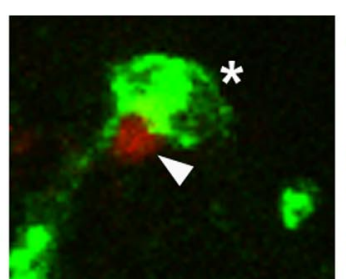

$2: 30$

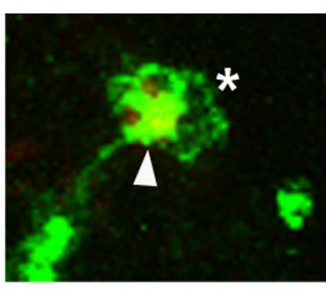

$3: 30$

Figure 8. Time-lapse imaging demonstrates that microglia contact and phagocytose VZ and SVZ cells. A-C, Microglia labeled with fluorescent lectins (green, asterisks) phagocytose DsRed + precursor cells (red, white arrowheads) in slice cultures. The microglia first contacted the precursor cells and then within $30 \mathrm{~min}$ to $10 \mathrm{~h}$ phagocytosed the DsRed + cells. B, Some microglia phagocytosed multiple precursor cells during time-lapse recording. Confocal optical plane imaging confirmed that DsRed + cells were located within labeled microglia. Imaging interval (h:m) for $\boldsymbol{A}$ and $\boldsymbol{B}$ is displayed at the top of the figure. Imaging interval for $\boldsymbol{C}$ is displayed at the bottom of the figure. Images in $\boldsymbol{A}$ and $\boldsymbol{B}$ were taken with a $10 \times$ objective; images in $\boldsymbol{C}$ were taken with a $40 \times$ objective.

|ba1/CC3/DAP|
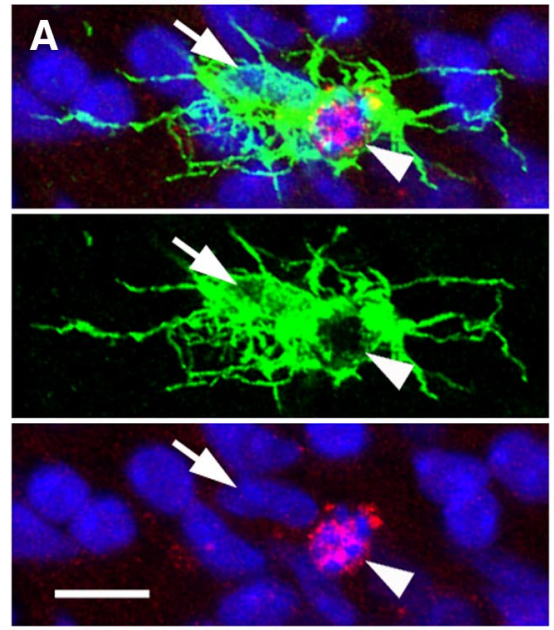

Iba1/Tbr2/PCNA

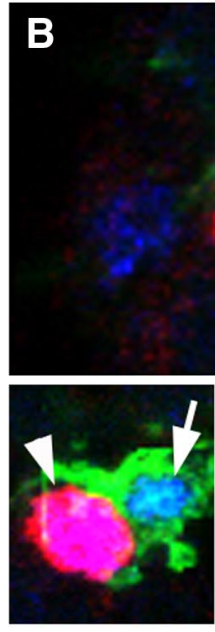

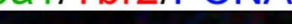

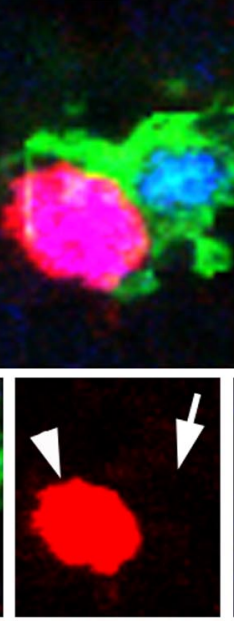

\section{Iba1/NeuN/DAPI}

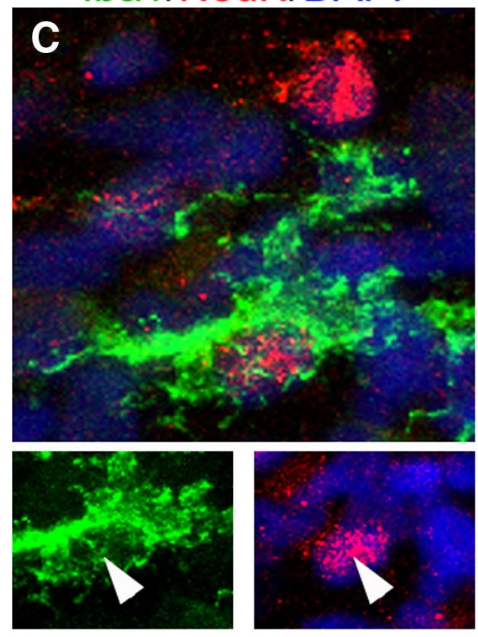

Figure 9. Iba1+ microglia (green) target and phagocytose apoptotic cells, mitotic neural precursor cells, and neurons in the proliferative zones. $A$, Iba $1+$ cells (green) target cleaved caspase 3 $(C(3)+$ cells (red, white arrowhead). The DAPI + nucleus (blue) of the lba $1+$ cell is indicated with a white arrow. The vast majority of targeted neural precursor cells were CC3-negative. $\boldsymbol{B}$, A Tbr2 + cell (red, arrowhead) expressing PCNA (blue) is targeted by an lba1+ microglial cell (green). The microglial cell is also PCNA + (blue, arrow). The majority of precursor cells targeted by microglia were PCNA+. C, lba1+ cells (green) also target NeuN + cells in the proliferative zones (red). Scale bar: (in A) A-C, $5 \mu \mathrm{m}$.

should increase the size of the precursor cell pool, while increasing the activation of microglia would decrease the size of the precursor cell pool. To test this hypothesis, we pharmacologically manipulated the activation state of microglia in the embryonic rat. To increase microglial activation, we modeled maternal immune activation by treating pregnant rats with bacterial LPS (Meyer et al., 2009; for review see Deverman and Patterson, 2009; Meyer, 2011; Hagberg et al., 2012). LPS produces a peripheral inflammatory cascade that is communicated to the brain via IL-1 $\beta$ (Monje et al., 2003; Barrientos et al., 2012) and activates microglial cells in the prenatal brain (Meyer et al., 2009; Meyer, 2011), increasing microglial phagocytosis (Neher et al., 2011), and local release of cytokines (Barrientos et al., 2012). Pregnant rats received two IP injections of LPS $(100 \mu \mathrm{g} / \mathrm{kg})$, one per day on E15 and E16. We suppressed microglial activation in utero with the tetracycline derivative doxycycline (Dox) (Yrjänheikki et al., 
1998; Jantzie et al., 2005; Lai and Todd, 2006; Maezawa et al., 2011), administered to pregnant rats in food pellets starting on E15 and continuing through postnatal day 10 (P10). Dox treatment inhibits microglial activation, but does not appear to inhibit the function of matrix metalloproteinases, which has been reported for other tetracycline derivatives (Jantzie and Todd, 2010). The proportion of Iba1 + cells with an activated morphology was decreased $\sim 30 \%$ in Dox-treated pups compared with controls $(p<0.05)$. The morphology of Ibal + cells did not differ in the LPS group versus controls, likely because the vast majority of Iba1 + cells $(>95 \%)$ already had an activated morphology in control embryos. However, the proportion of Iba1 + cells that expressed iNOS, a marker of activated Iba1 + cells (Verney et al., 2010 ), or the cytokine IL-1 $\beta$ (Barrientos et al., 2012) was increased nearly two-fold in the LPS group ( $p<0.05$, Fig. 10C,D, Table 1).

Macrophages and microglia can undergo classical M1 activation or alternative M2 activation, which represent two poles along a continuum of activation (Kigerl et al., 2009; Olah et al., 2011; Sica and Mantovani, 2012). We tested whether LPS or Dox treatment might push fetal microglia toward classical M1 "cytotoxic" activation or toward alternative M2 "neuroprotective" activation. We immunostained sections with antibodies against Iba1, and antibodies that label molecules associated with M1 activation (iNOS, IL-1 $\beta$ ) or M2 activation (arginase-1, IL-1RA). We quantified the ratio of microglia that expressed iNOS/ arginase-1, and IL-1 $\beta /$ IL-1RA in control, Dox, and LPS groups as a measure of M1/M2 polarization (Kigerl et al., 2009; Tarassishin et al., 2011). In control animals the proportion of microglia in the proliferative zones that expressed arginase-1 (19.3 \pm 3.0$)$ was not significantly different from the proportion that expressed iNOS (17.3 \pm 1.7$)$. The ratio of iNOS/arginase- 1 expression in control animals was 0.9 . LPS treatment significantly increased the proportion of microglia that expressed iNOS, with no effects on arginase- 1 expression, increasing the iNOS/arginase- 1 ratio to 1.36. In contrast, Dox treatment significantly increased the proportion of microglia that expressed arginase-1, but did not alter iNOS expression, decreasing the iNOS/arginase- 1 ratio to 0.43 (Table 1). These data suggest that maternal LPS treatment shifts fetal microglia toward M1 classical cytotoxic activation and that Dox treatment shifts cortical microglia toward M2 or neuroprotective activation. We next examined the ratio of IL-1 $\beta /$ Il-1RA expression in each group. In control animals the proportion of microglia that expressed IL-1 $\beta(22.7 \pm 3.7)$ was higher than the proportion that expressed IL-1RA $(14.0 \pm 3.3)$, but this difference was not quite significant $(p=0.07)$. The ratio of IL- $1 \beta / \mathrm{IL}-$ 1RA expression in controls was 1.8. Dox treatment decreased expression of IL-1 $\beta$ and increased IL-1RA expression (IL- $1 \beta / \mathrm{IL}-$ 1RA ratio $=0.7)$; consistent with the concept that Dox shifts fetal microglia toward M2 activation. However, while LPS treatment significantly increased IL- $1 \beta$ expression, IL-1RA expression was also significantly increased in the LPS group, increasing the IL$1 \beta /$ IL-1RA ratio for the LPS group (1.1) relative to the Dox group (0.7). Together, these data suggest that LPS and Dox treatment may produce different patterns of protein expression that reflect a differential polarity of activation in cortical microglia.

We next quantified the number of Tbr2+ and Pax6+ neural precursor cells in the control, Dox, and LPS groups at E19, $4 \mathrm{~d}$ after initiating treatment, and during postnatal stages of development. Precursor cell number was quantified in $200-\mu \mathrm{m}$-wide bins that spanned the proliferative zones in the developing cerebral cortex as previously described (Martínez-Cerdeño et al., 2012). Groups were compared with ANOVA and Tukey-Kramer post-comparison tests (Tables 1,2). During embryonic stages we found that LPS significantly reduced the number of Pax6+ cells by $40 \%(p<0.05)$, and the number of Tbr $2+$ cells by $20 \%(p<$ $0.01)$. In contrast, Dox treatment significantly increased the number of Pax6 + cells by $20 \%(p<0.01)$, and the number of Tbr $2+$ cells by $20 \%(p<0.01)$. The thickness of the VZ/iSVZ was also reduced $20 \%$ in the LPS group $(p<0.01$, Fig. $10 A, B)$. Previous studies have reported that maternal LPS treatment reduces the proliferation of ventricular cells in the embryonic neocortex within $8 \mathrm{~h}$ after treatment (Stolp et al., 2011). To test whether decreased proliferation contributed to the decreased number of Pax6 + and Tbr2 + cells in the LPS group, we quantified the number of PH3 + cells in 200- $\mu \mathrm{m}$-wide radial bins of the dorsal neocortex in motor/sensory cortex of the control and LPS groups $4 \mathrm{~h}$ after the second LPS injection on E16. We found no difference in the number of $\mathrm{PH} 3+$ mitoses in the VZ (control: $16.0 \pm 1.2$ mitoses per bin; LPS: $17.1 \pm 1.5$ mitoses per bin; $p=0.54)$, SVZ (control: $10.9 \pm 1.5$ mitoses per bin; LPS: $12.5 \pm 1.4$ mitoses per bin; $p=0.43$ ), or in the total number of mitoses (control: $26.94 \pm$ 1.50 mitoses per bin; LPS: $29.53 \pm 2.73$ mitoses per bin; $p=0.44$; $n=6$ control animals, 298 cells; 5 LPS animals, 269 cells). We tested whether the altered number of neural precursor cells in the Dox- and LPS-treated embryos resulted from changes in cell death and found a slight increase in the number of CC3 + cells per hemisphere in the LPS group that was not significant (Fig. 10E).

We investigated whether Dox or LPS treatment produced persistent changes in the number of neural precursor cells in postnatal animals. We quantified the number of Pax6+ and Tbr2+ cells at $\mathrm{P} 2$ and found that the number of Tbr $2+$ cells was reduced by $20 \%$ nearly $10 \mathrm{~d}$ after LPS treatment $(p<0.05$, Fig. $10 F, G)$. In contrast, the number of Pax6 + cells and Tbr2 + cells was 50\% greater in Dox-treated pups compared with controls $(p<0.01$, Fig. $10 F, G)$. The increase in precursor cell number persisted in Dox-treated pups until at least P10. We also quantified the thickness of the VZ/iSVZ at P2 and found that it was slightly thinner in the LPS group and significantly thicker in the Dox-treated pups $(p<0.01$, Fig. $10 F, G)$.

We next tested whether the altered number of precursor cells in the postnatal neocortex of experimental pups was related to changes in cell death. The number of CC $3+$ cells was reduced by nearly $40 \%$ in the neocortex of P2 Dox-treated pups $(p<0.05$, Fig. $10 \mathrm{H}$ ). This is consistent with the idea that microglia may play a role promoting cell death in the prenatal cerebral cortex (Deverman and Patterson, 2009). However, the LPS group did not show evidence of significant changes in cell death. We tested whether manipulating microglial phagocytosis of neural precursor cells altered the number of neurons produced in the developing brain by quantifying the number of NeuN + cells in the proliferative zones of each group. We found a large significant increase in the number of NeuN + cells in the SVZ of the Dox-treated group ( $p<0.01$, Fig. $10 I$ ).

We also tested the capacity of minocycline to deactivate microglia in the prenatal cerebral cortex, since previous work has shown that minocycline reduces the activation state of microglia (Yrjänheikki et al., 1998; Tikka et al., 2001; Ekdahl et al., 2003; Fan et al., 2007). We prepared organotypic slice cultures from the cerebral cortex of E16 rats and supplemented the media of experimental slices with minocycline $(100 \mu \mathrm{m})$. After $3 \mathrm{~d}$ in vitro we fixed the slices, immunostained for Ibal and Tbr2, and quantified the number of cells in $200-\mu$ m-wide bins that extended radially from the ventricular surface through the proliferative zones. The number of Iba1+ cells was reduced, but not significantly different in minocycline-treated slices. However, the number of 
A
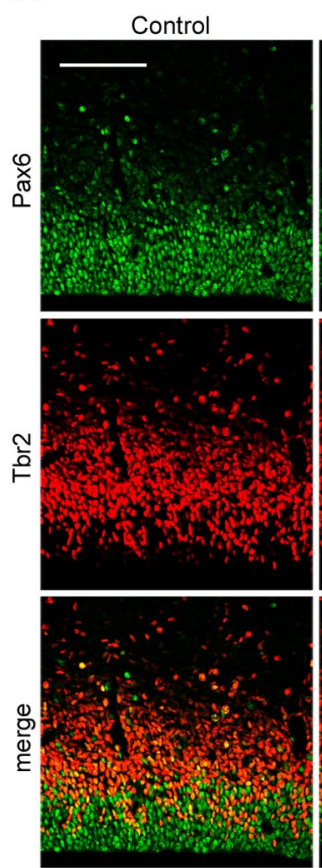

B

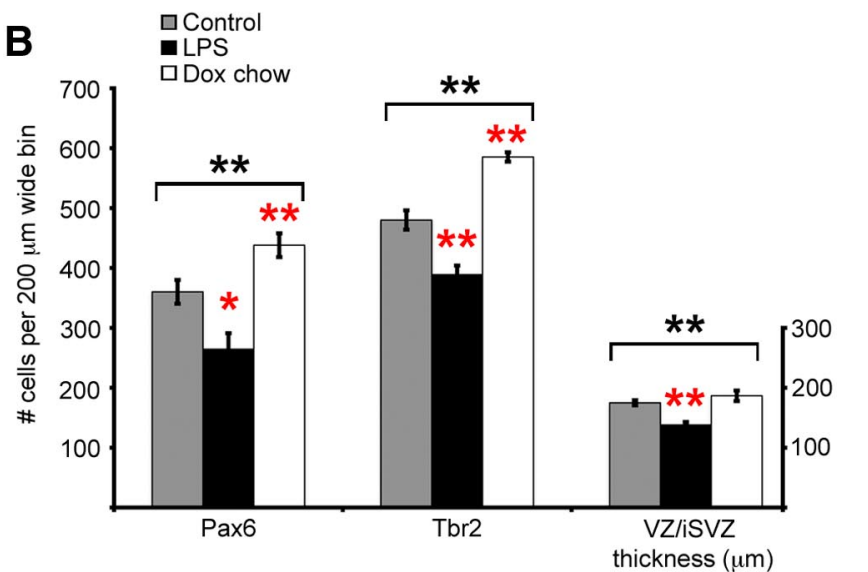

C

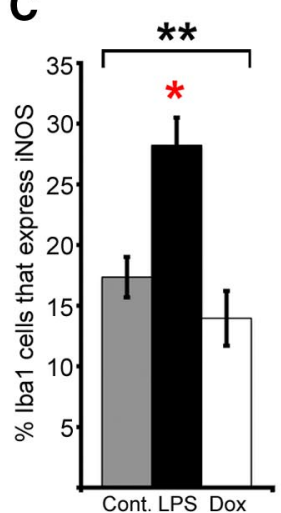

E19 neocortex
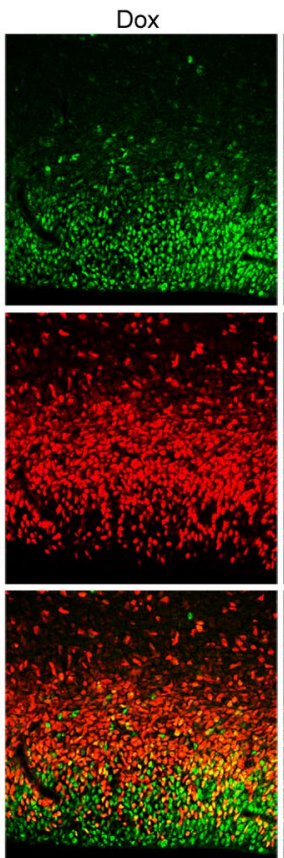
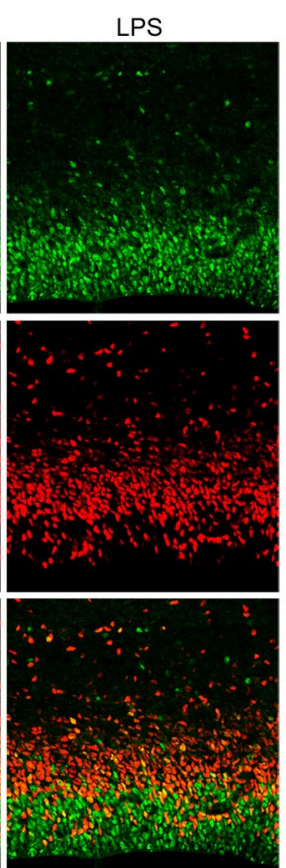

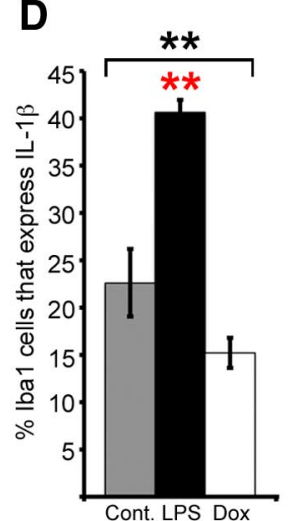

E

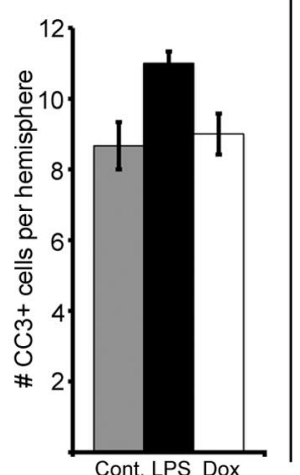

F
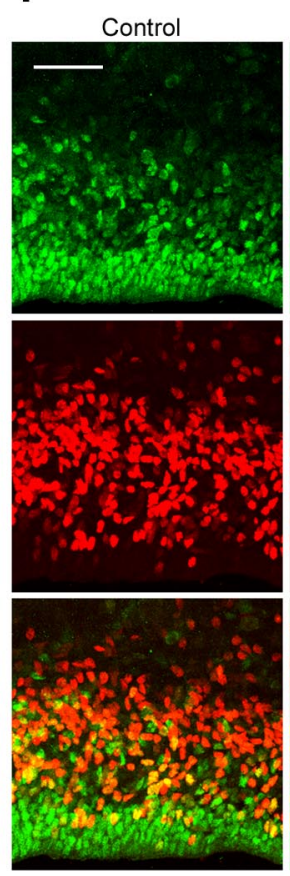

G

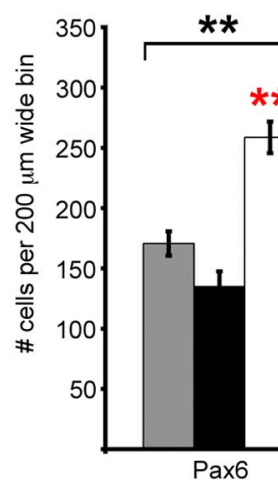

H

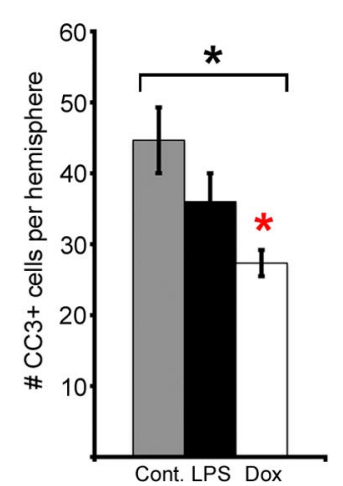

P2 neocortex Dox
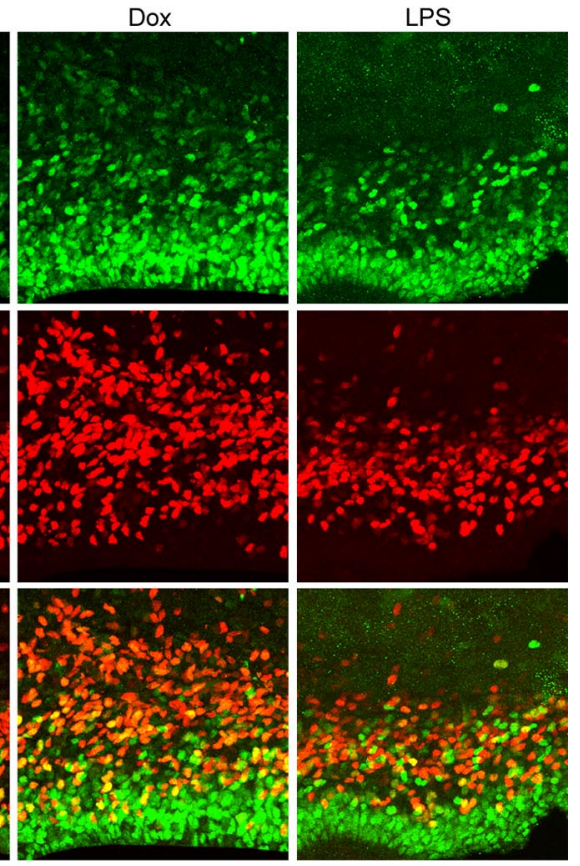

$\square$ Control

- LPS

口Dox chow

Figure 10. Manipulating the activation state of microglia changes the number of neural precursor cells in the prenatal brain. The number of Pax6 + and Tbr2 + precursor cells was quantified in 200 - $\mu \mathrm{m}$-wide bins that spanned from the ventricular surface through the proliferative zones at E19 and at P2. A, B, At E19 Dox treatment significantly elevated the number of Tbr2 + cells per bin, while LPS treatment significantly reduced the number of Pax6 + and Tbr2 + cells per bin, and reduced the combined thickness of the VZ/iSVZ.C, D, LPS treatment increased the proportion of Iba1+ cells that express high levels of iNOS, a marker of activated microglia (Verney et al., 2010), and the proportion of Iba1 + cells that expressed high levels of the cytokine IL-1 $\beta$. The proportion of Iba1+ cells that expressed these markers was slightly decreased in the Dox group. $\boldsymbol{E}$, LPS slightly elevated the number of CC + cells per hemisphere, but the difference was not significant. $\boldsymbol{F}, \boldsymbol{G}$, At $P 2$ Dox treatment significantly increased the number of Pax6 + and Tbr2 + cells and increased the combined thickness of the VZ/iSVZ, while LPS significantly decreased the number of Tbr $2+$ cells. $\boldsymbol{H}$, Dox treatment significantly reduced the number of CC3 + cells per hemisphere. I, Dox treatment significantly increased the number of NeuN + cells in the oSVZ. Brackets denote ANOVA significance, ${ }^{*} p<0.05 ;{ }^{* *} p<0.01$. Red asterisks indicate post hoc significance, single red asterisk: $p<0.05$; double red asterisk: $p<0.01$. Error bars show SE. Scale bars: $\boldsymbol{A}, 100 \mu \mathrm{m} ; \boldsymbol{B}, 50 \mu \mathrm{m}$. 
A

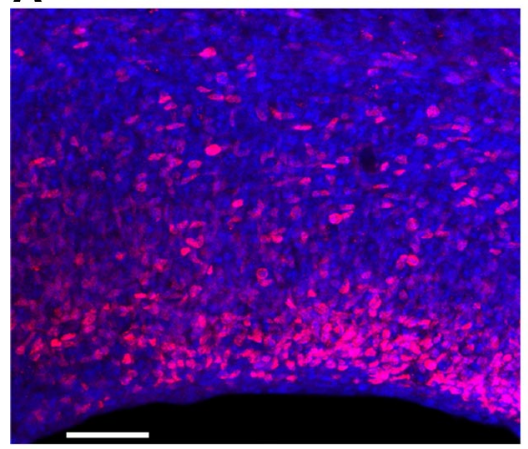

B

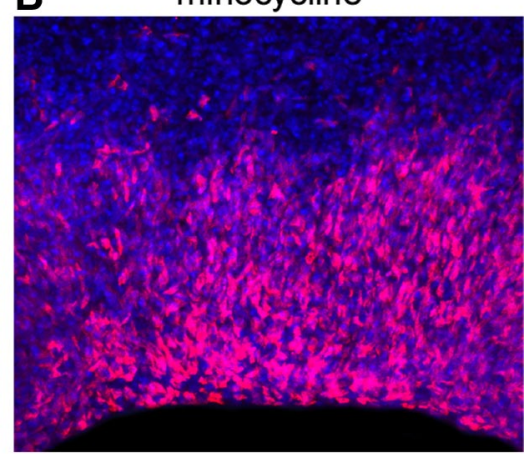

In vitro organotypic slices

Figure 11. Minocycline treatment significantly increased the number of Tbr2 + neural precursor cells in the prenatal proliferative zones. $A$, A control organotypic slice after 3 din culture stained for Tbr $2+$ precursor cells (red) and DAPI (blue). $\boldsymbol{B}$, The number of Tbr2 + cells was significantly increased in slices treated for $3 \mathrm{~d}$ with $100 \mu \mathrm{m}$ minocycline. Scale bar, $50 \mu \mathrm{m}$. cells in 200- $\mu$ m-wide bins that extended from the ventricle through the proliferative zones. In neocortex depleted of microglia through exposure to liposomal clodronate the number of Pax6 + cells was significantly increased, and this difference was most prominent in the oSVZ. In control animals there were $30.9 \pm 9.7$ Pax $6+$ cells per bin in the oSVZ, while in clodronate-treated animals the number of Pax6+ cells was increased $>3$-fold to $108.8 \pm 20.2$ Pax $6+$ cells $(p<0.05$; Fig. 12E,F). The number of Tbr2+ neural precursor cells was also significantly increased in the absence of microglia (control: $45.6 \pm 14.9$ Tbr2+ cells; liposomes: $118.2 \pm 7.5$ Tbr2 + cells; $p<$ 0.01; Fig. 12G,H).

Together, our results show that manipulating the activation state of fetal mi-

Tbr $2+$ precursor cells was significantly increased nearly twofold in minocycline-treated slices. There were $393.7 \pm 30.4$ Tbr2+ cells in the SVZ of control slices, and 723.0 \pm 32.6 Tbr2 + cells in the SVZ of minocycline-treated slices (Fig. 11).

\section{Eliminating microglia increases the number of neural precursor cells in the neocortex}

Since deactivating microglia pharmacologically increased the number of neural precursor cells, we asked whether eliminating microglia from the cerebral cortex would have the same effect on the size of the neural precursor cell pool. We prepared organotypic slices from the embryonic rat cerebral cortex and included liposomal clodronate in the culture media of experimental slices. Liposomal clodronate has been shown to selectively target and kill macrophages and microglia while sparing other cell types (Van Rooijen and Sanders, 1994; Drabek et al., 2012; Kumamaru et al., 2012). Clodronate itself does not cross cell membranes, and for that reason is not toxic and is FDA approved for treatment of human bone conditions (Välimäki et al., 2002). However, clodronate encapsulated in liposomes is taken up by macrophages and microglia through phagocytosis and when concentrated inside the cell causes cell death (Van Rooijen and Sanders, 1994). We found that liposomal clodronate eliminated over $95 \%$ of Iba1+ microglia in organotypic slice cultures (Fig. 12A,B). We next tested the effectiveness of liposomal clodronate in vivo. We performed in utero intracerebral injections of clodronate liposomes into the lateral ventricle of E16 and E20 embryos. One to three days later we killed the animals and prepared sections for immunostaining with antibodies to label neural precursor cells (Pax6, Tbr2) and microglia (Iba1). At E17, 1 d after E16 in utero liposome injections, there was a significant decrease in the number of microglia. We quantified the number of Tbr2 + neural precursor cells in the E17 dorsolateral neocortex in 200 - $\mu \mathrm{m}$-wide bins and found a significant increase in the number of Tbr2+ cells (control: $575.3 \pm 12.5$ Tbr2 cells; liposomes: $712.8 \pm 23.1$ Tbr2 cells; $p<0.01$ ). Three days after E20 in utero intracerebral injections of liposomal clodronate, there was a dramatic $90 \%$ decrease in the number of microglia in the developing cerebral cortex (Fig. 12C,D). CC3 immunostaining showed that liposomal clodronate did not produce a generalized increase in cell death in the cerebral cortex. On the contrary, there was a significant increase in the number of neural precursor cells in brains from which microglia had been eliminated by liposomal clodronate. We quantified the number of Pax6+ and Tbr2+ neural precursor croglia by inducing MIA with LPS, or in utero administration of the microglial inhibitors doxycycline or minocycline, alters the number of neural precursor cells in the embryonic and early postnatal brain. Likewise, eliminating microglia in the fetal cerebral cortex through in utero administration of liposomal clodronate significantly increases the number of neural precursor cells. These data support the hypothesis that microglia play a central role in regulating cortical neurogenesis by controlling the number of neural precursor cells.

\section{Discussion}

The size of the precursor cell pool decreases during late stages of cortical neurogenesis (Bayer and Altman, 1991; Smart et al., 2002). Several mechanisms that contribute to the thinning of the proliferative zones have been identified. For example, radial glial cells that translocate out of the VZ (Schmechel and Rakic, 1979; Voigt, 1989; deAzevedo et al., 2003; Noctor et al., 2004; Noctor et al., 2008) and express Pax6 (Fietz et al., 2010; Hansen et al., 2010; Martínez-Cerdeño et al., 2012) contribute to a reduction in the size of the VZ precursor cell pool. Symmetric terminal divisions of intermediate progenitor cells that produce two neurons and thereby deplete the neural precursor cell may reduce the size of the SVZ precursor cell pool (Cai et al., 2002; Noctor et al., 2004, 2008). It has not been determined whether these mechanisms are sufficient for depleting the number of precursor cells in the VZ and SVZ, or if additional mechanisms contribute to the reduction of neural precursor cell number at the end of neurogenesis. Regressive events have long been recognized as playing important roles in brain development (Cowan et al., 1984), with much attention focused on trophic support and selective elimination of postmitotic neurons. We show here that microglia play a previously unrecognized role in reducing the size of the precursor cell pool, particularly during later stages of cortical neurogenesis (Figs. 6, 7). The elimination of neural precursor cells by microglia at the end of cortical neurogenesis suggests several possibilities including: (1) that a surplus of precursor cells are generated during cortical development and excess cells are culled by microglia; (2) that trophic signals maintaining precursor cells in a proliferative state are downregulated at the end of neurogenesis, allowing for phagocytosis; or (3) that targeted neural precursor cells may be recognized as defective in some way. Microglia are highly sensitive to physiological and pathological changes (Deverman and Patterson, 2009), and could perhaps identify precursor cells that accumulate chromosomal errors or exhibit oxidative stress dur- 


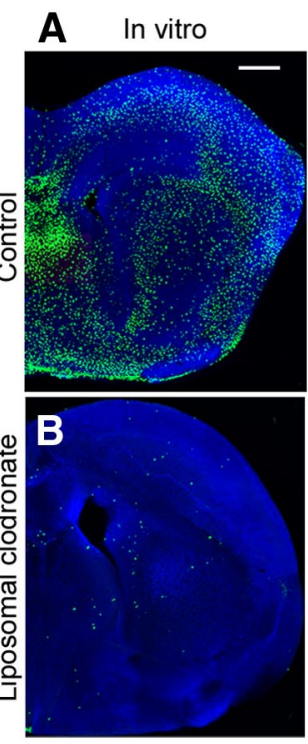

In vivo: control
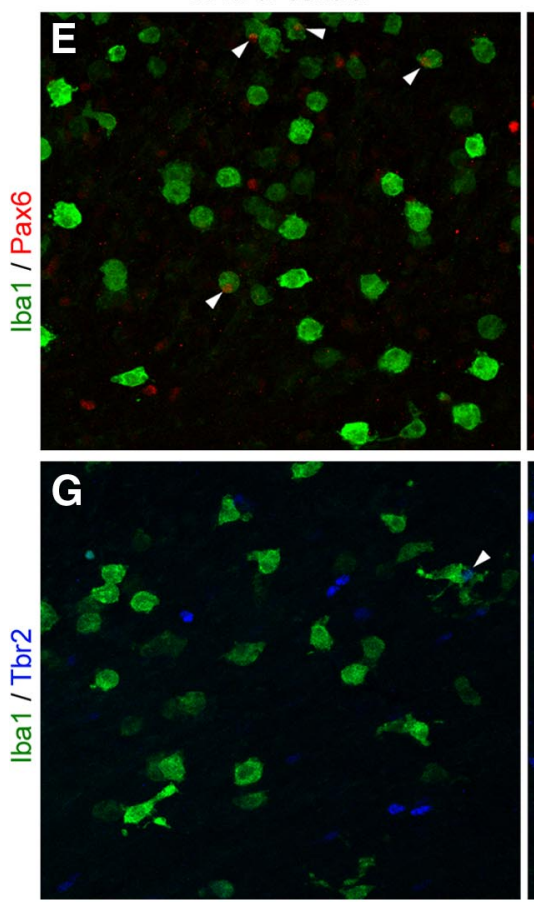

P1 In vivo: control

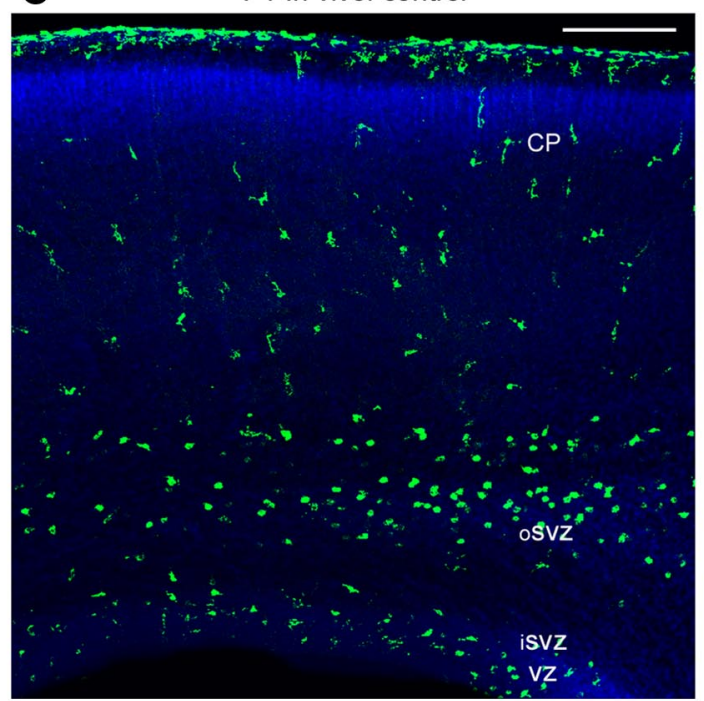

In vivo: liposomal clodronate

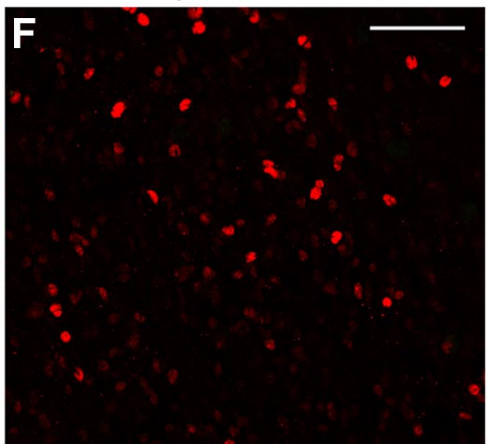

H

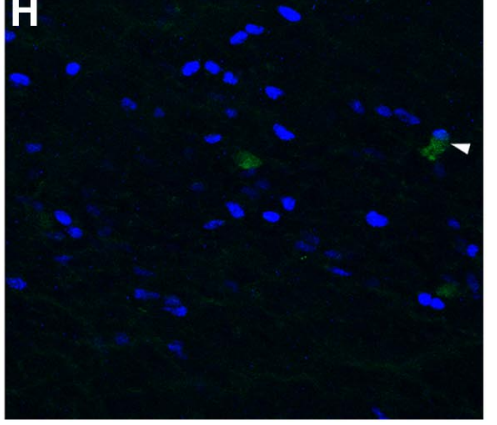

D

P1 In vivo: liposomal clodronate

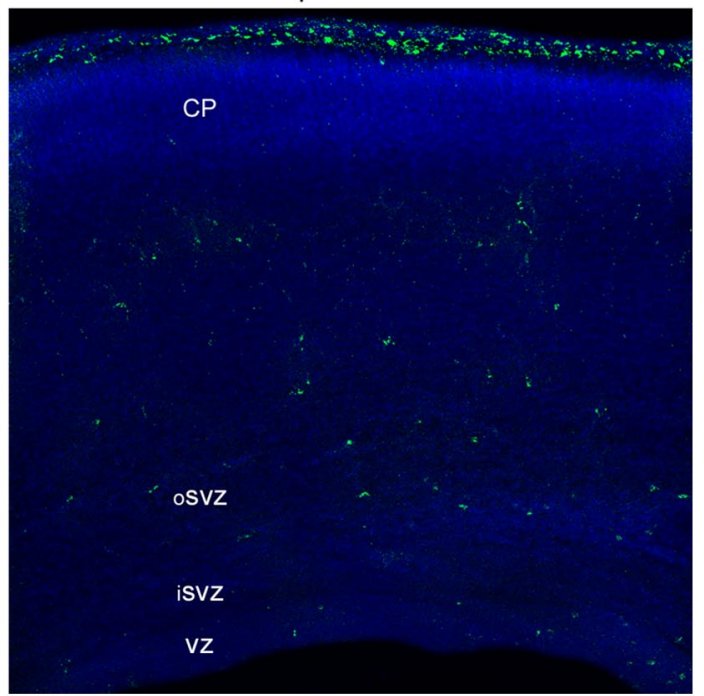

Figure 12. Eliminating microglia from the developing cerebral cortex increases the number of neural precursor cells. $A$, Iba $1+$ microglia (green) populate an organotypic slice prepared from the E16 cerebral cortex and cultured for $3 \mathrm{~d}$. B, Addition of liposomal clodronate to the culture media for the first $24 \mathrm{~h}$ in culture eliminated $97 \%$ of microglia from the cerebral cortex. $\boldsymbol{C}$, A coronal section of a P1 rat brain stained for microglia (green) and nuclei (DAPI, blue). Microglia populate the proliferative zones. $D$, The number of microglia in the $\mathrm{P} 1$ cerebral cortex is reduced by $90 \%$ after in utero intraventricular injections of liposomal clodronate at E20.A-D, DAPI (blue). $E, F$, Liposomal clodronate decreases the number of microglia (green) and significantly increases the number of Pax6 + precursor cells (red) and Tbr2+ precursor cells $(\boldsymbol{G}, \boldsymbol{H})$. White arrowheads indicate precursor cells targeted or phagocytosed by microglial cells. $\boldsymbol{I}$, Histogram showing that $3 \mathrm{~d}$ after E20 in utero intraventricular injection of liposomal clodronate there is a significant decrease in the number of microglia, and a significant increase in the number of Pax6 + cells and Tbr2 + cells. Double red asterisk: $p<0.01$; single red asterisk: $p<0.05$. Scale bars: $A, 500 \mu \mathrm{m} ; C, 200 \mu \mathrm{m} ; F, 50 \mu \mathrm{m}$.

ing highly proliferative stages of development. However, we did not find evidence of elevated levels of apoptosis among targeted precursor cells, nor did we observe other signs of cell death among targeted precursor cells. Previous work has shown that microglia can phagocytose viable neurons (Fricker et al., 2012; Neher et al., 2012); our data are consistent with the idea that microglia phagocytose viable precursor cells in the neural proliferative zones. Recent work has shown that microglia participate in synaptic pruning in the developing postnatal brain (Paolicelli et al., 2011; Schafer et al., 2012), and phagocytose newborn neu- rons in the subgranular zone of the adult hippocampus (Sierra et al., 2010). Our findings increase the repertoire of microglial functions by demonstrating that under normal conditions they regulate the size of the neural precursor cell pool in the developing cerebral cortex. We cannot rule out the possibility that microglia perform other vital functions and interact with cells in the prenatal proliferative zones through cytokine and or chemokine signaling. Indeed, previous work has shown that cytokines can influence the function of neural stem cells (Carpentier and Palmer, 2009; Deverman and Patterson, 2009). Our results add to this body of work by showing 


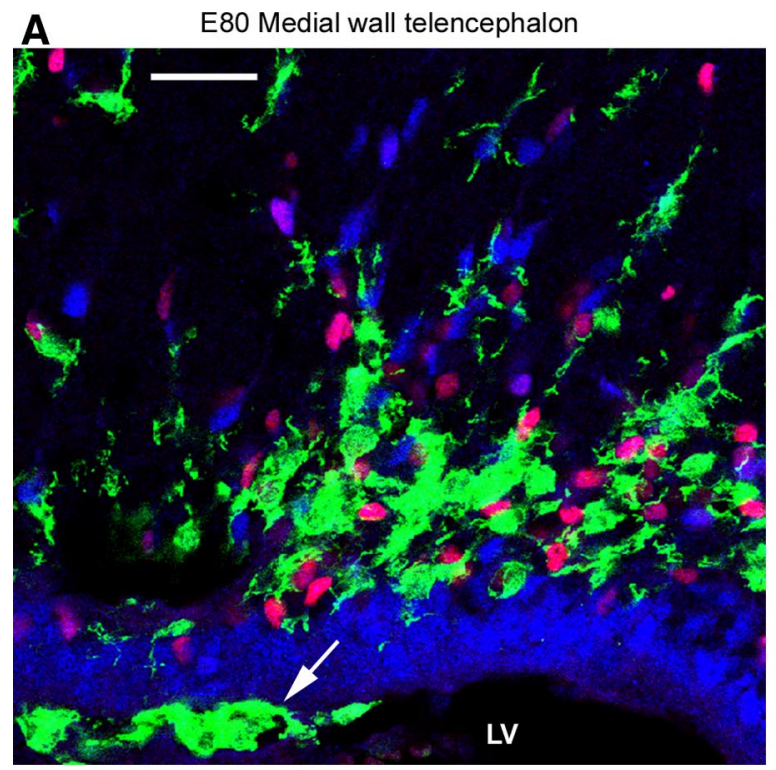

|ba1 / Tbr2 / DAPI

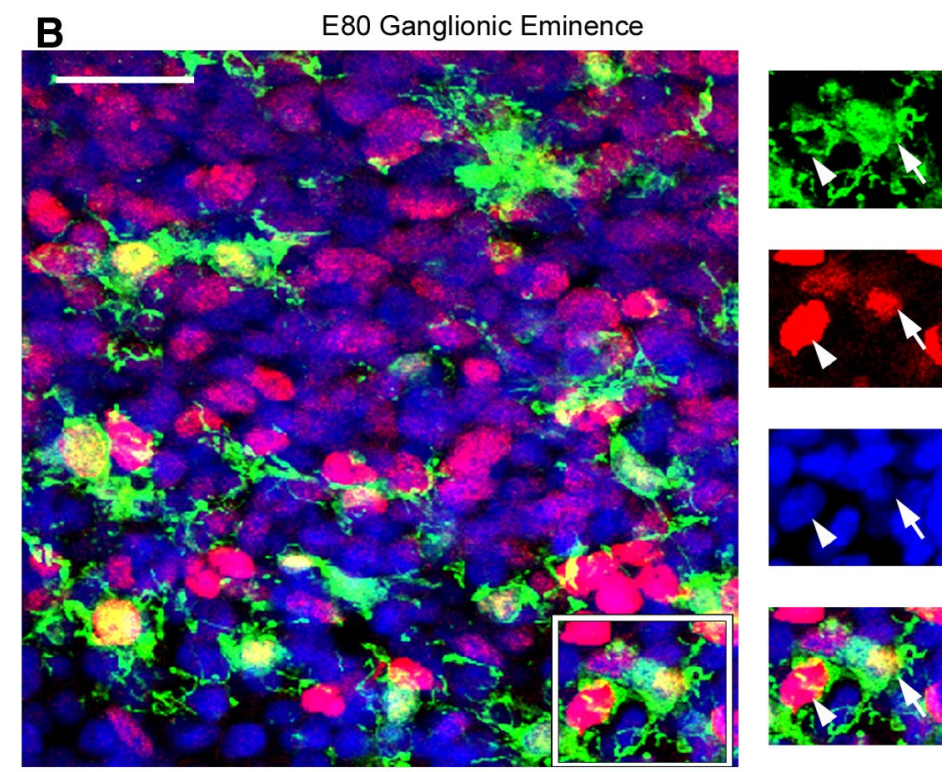

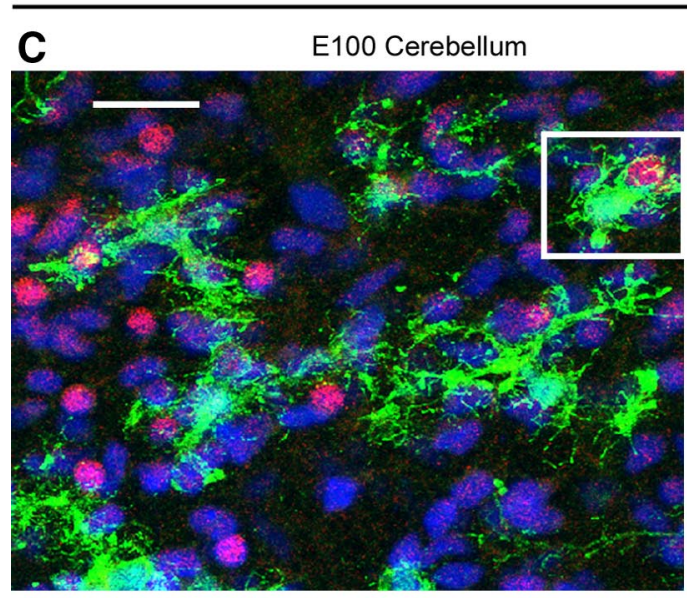

Iba1 / Pax6 / DAPI

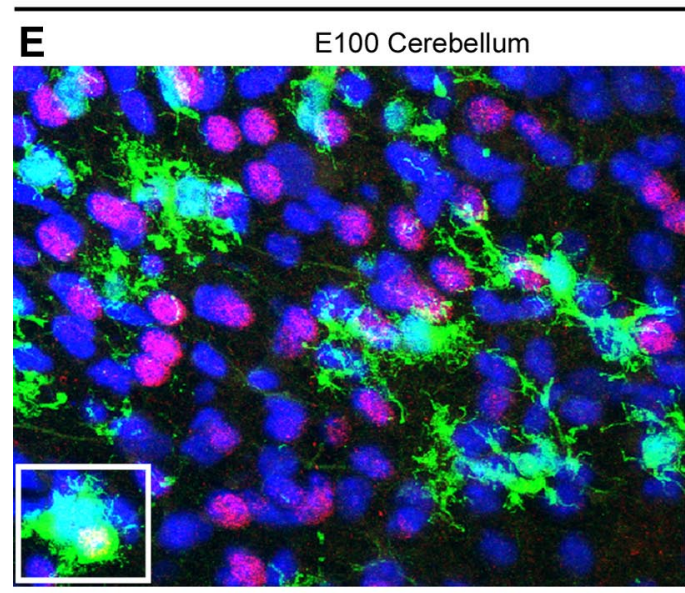

Iba1 / Pax6 / DAPI
Iba1 / PCNA / DAPI
D E100 Cerebellum
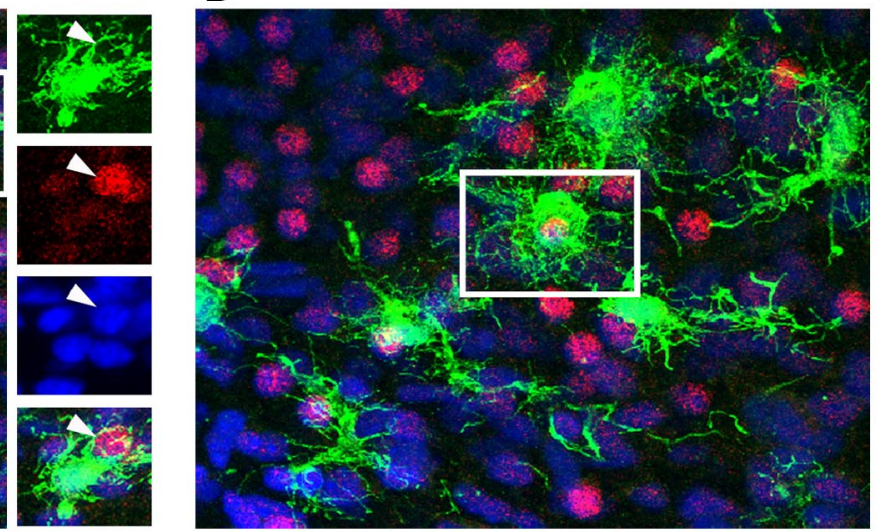

|ba1 / Pax6 / DAPI

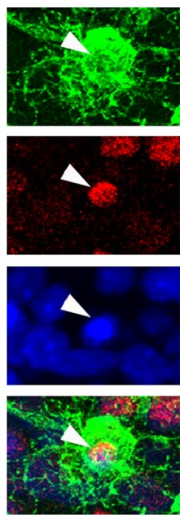

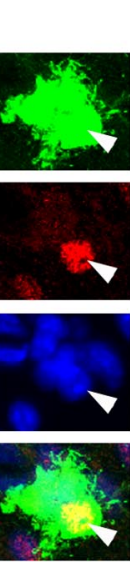

Gen

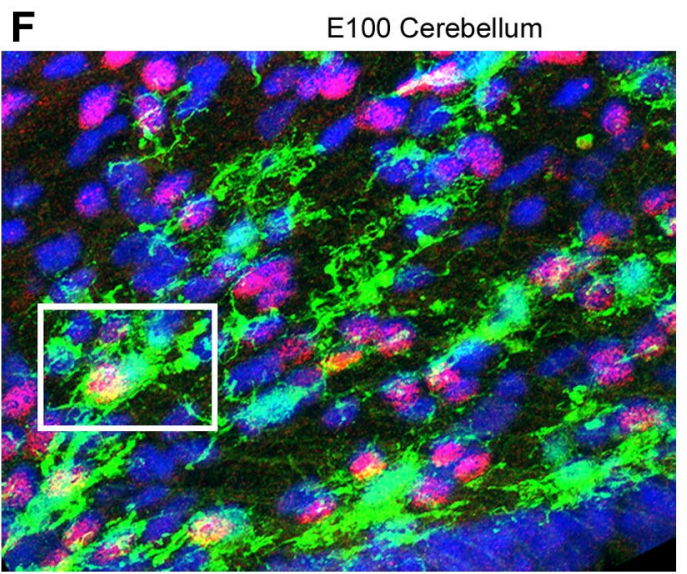

|ba1 / Pax6 / DAP|

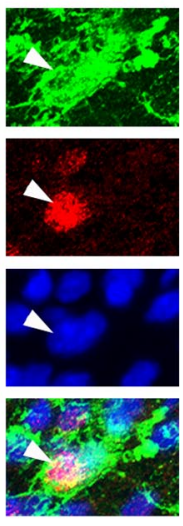

100

Figure 13. Iba1 + microglia colonize proliferative regions in multiple structures in the developing macaque CNS. $A$, lba $1+$ microglia (green) colonize proliferative zones in the medial wall of the telencephalon of E80 macaques where they target Tbr2 + precursor cells (red). Microglial often migrate along the surface of the lateral ventricle (arrow). $\boldsymbol{B}$, lba1 + microglia (green) colonize the proliferative zones of the E80 macaque ganglionic eminence and target PCNA + precursor cells (red). Insets show phagocytosed PCNA+ precursor cells (arrowheads) within Iba1+ microglia (arrows). C-F, Iba1+ cells (green) are present in the E100 macaque cerebellum where they target Pax6+ precursor cells (red, arrowheads). Scale bars, $20 \mu \mathrm{m}$. Blue, DAPI. LV, Lateral ventricle. 
A

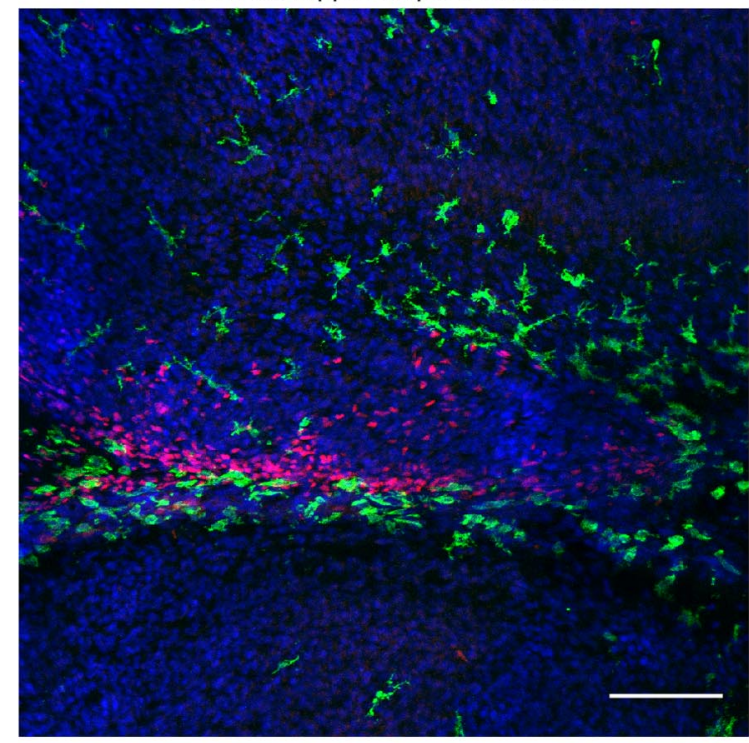

Iba1 / Tbr2 / DAPI

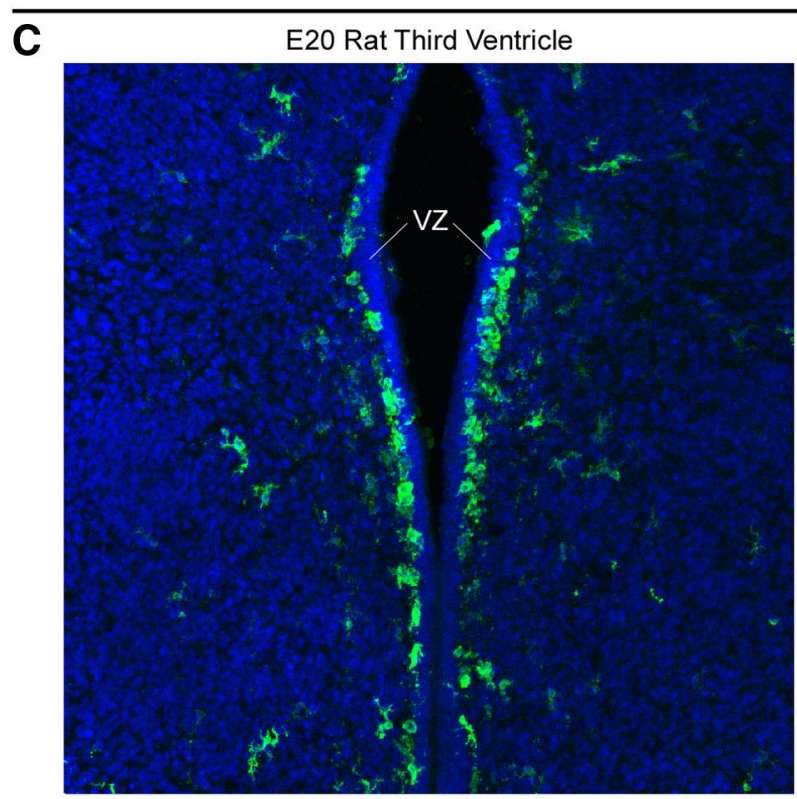

|ba1 / DAPI
B

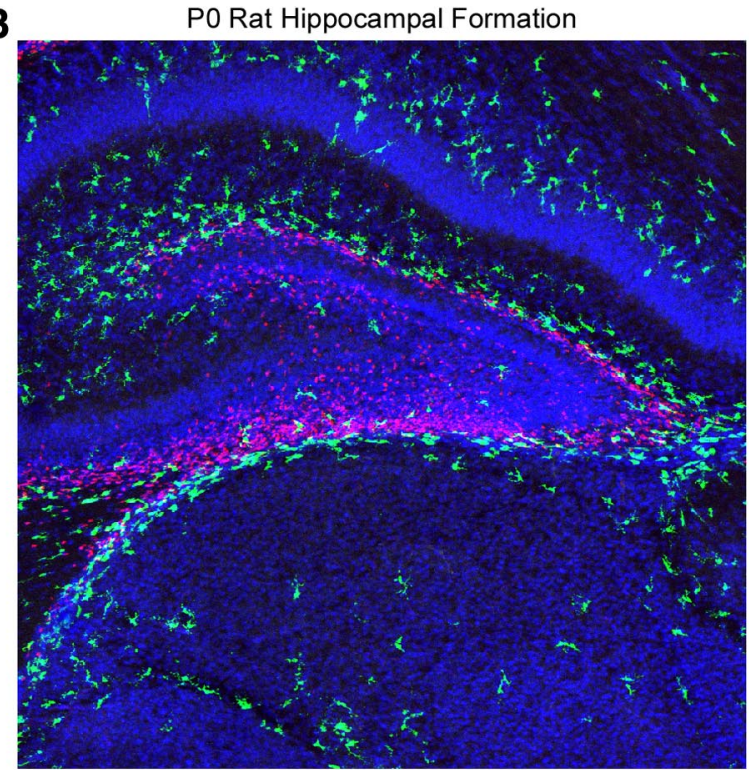

lba1 / Tbr2 / DAPI
D

D

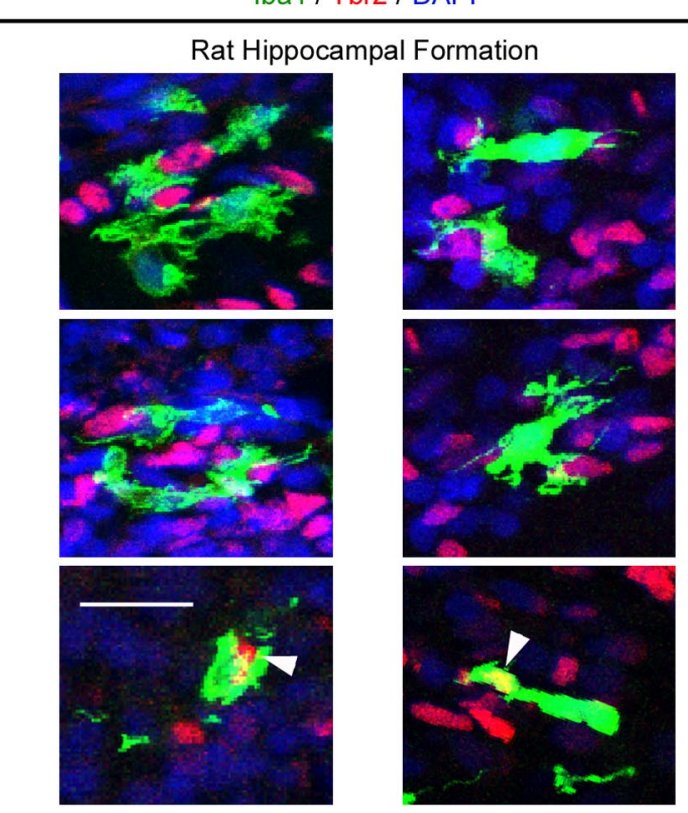

|ba1 / Tbr2 / DAPI

Figure 14. Iba1+ microglia colonize proliferative regions in multiple structures in the developing rat brain. $\boldsymbol{A}, \mathrm{lba} 1+$ microglia (green) colonize proliferative zones in the developing hippocampal formation of the E20 rat where they target Tbr2+ precursor cells (red). $\boldsymbol{B}, \mathrm{Iba} 1+$ microglia (green) concentrate around proliferative Tbr2+ precursor cells (red) in the subpial neurogenic zone (Li et al., 2009) of the developing hippocampal formation in PO rat where they target Tbr2 + precursor cells (red). Iba1 + microglia also target Tbr2-negative cells in the developing hippocampal formation. C, Iba1+ microglia (green) form a monolayer immediately superficial to the proliferative ventricular zone (VZ) of the E20 rat third ventricle. $\boldsymbol{D}$, Examples of Iba $1+$ microglia (green) targeting and phagocytosing Tbr2 + precursor cells (red) in the developing hippocampal formation of E20 and P0 rat. White arrowheads indicate Tbr2 + cells enveloped by lba1 + microglia. Images are optical plane sections obtained from a confocal microscope. Blue, DAPI. Scale bars: (in $\boldsymbol{A}) \boldsymbol{A}-\boldsymbol{C}, 100 \mu \mathrm{m} ; \boldsymbol{D}, 20 \mu \mathrm{m}$.

that microglia regulate neuron production in the prenatal brain directly by phagocytosing neural precursor cells.

We observed microglial phagocytosis of precursor cells in multiple regions of the developing CNS in macaque and rat (Figs. $13,14)$. In addition, we found that microglia phagocytose precursor cells during and after neurogenic stages of cortical development, suggesting that microglia regulate the number of glial precursor cells during cortical development. Together, these data provide compelling evidence that microglia play a fundamental role in limiting cell production and ultimately regulating the size of the cerebral cortex and other CNS structures. Furthermore, our finding that the location of Iba1 + cell bands varies across cortical areas (Fig. 3) suggests the possibility that microglia contribute to the development of cytoarchitectural and functional differences across cortical areas.

Previous work has shown that microglia participate in shaping neurogenesis in the adult brain. For example, it has been reported that microglia release factors such as TGF- $\beta$, which influences the proliferation of neural precursor cells (Battista et al., 2006); that inflammation is detrimental for neurogenesis in the adult hippocampus (Ekdahl et al., 2003; Monje et al., 2003); that minocycline (Ekdahl et al., 2003) or indomethacin (Monje et al., 2003) attenuate impaired neurogenesis in the hippocampus caused by LPS treatment; that properly functioning immune cells are nec- 
essary for neurogenesis in the adult hippocampus (Ziv et al., 2006); and that microglia phagocytose newly born neurons in the adult hippocampus (Sierra et al., 2010). The presence of microglia in the neurogenic adult SVZ has also been noted (Goings et al., 2006). Recent work has also shown that neural precursor cells in the adult brain may shape the activity of microglial cells through release of vascular endothelial growth factor (Mosher et al., 2012). This work taken together with our present findings strongly suggests that microglia shape cell genesis in the CNS from prenatal stages of development into adulthood.

Our data show that LPS-mediated maternal immune activation reduces the size of the neural precursor cell pool (Fig. 10), and we propose that this occurs through microglial phagocytosis. LPS increases the number of microglia in the neurogenic niche of the adult hippocampal subgranular zone (Monje et al., 2003) and reduces adult hippocampal neurogenesis (Ekdahl et al., 2003; Monje et al., 2003). Monje et al. (2003) prepared mixed precursor/microglial cell culture experiments and showed that LPS increases cell death and that the antineurogenic effect of LPS in the adult hippocampus is mediated by microglial release of soluble cytokines. However, we did not observe signs of increased cell death in the perinatal brain on E17, E19, or P2 after LPS administration on E15 and E16. In support of our findings that microglia can regulate the size of the neural precursor cell pool in the embryonic cerebral cortex directly through phagocytosis, we show through time-lapse microscopy that microglia perform this function in vitro (Fig. 8). Furthermore, Neher et al. (2011) have shown that adding LPS to mixed neuronal/microglia cultures reduces neuronal number without increasing apoptosis or cell death and works exclusively through microglial phagocytosis. In addition, previous studies have reported that microglia in the fetal rodent neocortex are phagocytic (Kaur et al., 2007). While we cannot rule out the possibility that maternal immune activation impacts neural precursor cells in the developing brain via multiple pathways, our data suggest that LPS does not induce cell death in the embryonic cortex. We propose that microglia are key effectors of maternal immune activation and can impact development of the prenatal brain directly through phagocytosis. To date, studies of adult neurogenic zones have not reported microglial phagocytosis of neural precursor cells. This likely reflects key differences between embryonic and adult cell genesis. The embryonic cortical proliferative zones house vast numbers of neural precursor cells that are no longer needed after neurogenesis. In contrast, the adult hippocampus has a comparatively limited number of precursor cells that produce neurons throughout life. Substantial phagocytosis of precursor cells in the adult hippocampus could eliminate neural stem cells that are required for ongoing neurogenesis. Animal models of maternal immune activation mimic bacterial infection with LPS and viral infection with poly I:C (Meyer et al., 2009). Future studies should compare the effects of the LPS and poly I:C models on neural precursor cells in the prenatal cerebral cortex.

Numerous publications have highlighted the consequences of an inflammatory immune response during brain development (Deverman and Patterson, 2009; Meyer et al., 2009; Meyer, 2011; Hagberg et al., 2012). Maternal influenza during the first trimester has been associated with schizophrenia (Brown et al., 2004), and studies have reported reduced gray matter volume in some cortical regions of schizophrenic patients (Rais et al., 2012). In particular, an association between the strength of psychotic symptoms and cortical thickness reductions in patients with schizophrenia has been reported (Oertel-Knöchel et al., 2012). Maternal immune activation has also been linked to a growing number of neurodevelopmental disorders including autism (Hagberg et al., 2012). In that respect, studies have reported increased numbers of activated microglial cells in the autistic neocortex (Morgan et al., 2010), decreased neuronal number in the autistic fusiform gyrus (van Kooten et al., 2008) and amygdala (Amaral et al., 2008), and susceptibility to decreased neuronal number in the amygdala of rodents exposed to LPS-mediated MIA (Spencer et al., 2006). These data are consistent with the idea that gestational MIA increases the activation of fetal microglia in the developing cortex, elevating the level of phagocytosis of cortical precursor cells, and that this may be correlated with the decreased gray matter volume or cell numbers reported in some CNS structures in neurodevelopmental disorders. Furthermore, our data showing that the number of microglia in the primate SVZ varies temporally during prenatal cortical development (Fig. 1) may provide a mechanism to help explain why the timing of maternal immune activation during gestation has a differential impact on neuropathology and behavior (Meyer et al., 2006).

While augmenting microglial activation with LPS reduces precursor cell number, we found that suppressing microglial activation in utero increases the size of the neural precursor cell pool in the neocortex (Fig. 10) and significantly increases the number of NeuN + cells in the proliferative zones (Fig.10I). These data are consistent with the concept that suppressing microglial activation shifts the homeostatic balance of microglial phagocytosis and spares a greater proportion of neural precursor cells, and is also consistent with in vitro studies that found that blocking microglial phagocytosis increases neuronal number in cell culture (Neher et al., 2011). Pathological conditions could potentially decrease microglial activation in the prenatal cerebral cortex and impact brain development. For example, vasoactive intestinal peptide, which decreases microglial activation and release of IL-1 $\beta$ (Delgado and Ganea, 2003), is reportedly overexpressed in autistic subjects (Nelson et al., 2001). In light of our present findings, this suggests the possibility that suppressed microglial activation in the prenatal brain could be correlated with larger brain size (Amaral et al., 2008), and the increased number of neurons in the prefrontal cortex that has been reported for some autistic subjects (Courchesne et al., 2011). Neurodevelopmental disorders in general, and autism spectrum disorders in particular, have diverse etiologies. Our data suggest that alterations of microglial activation during brain development may contribute to the neuroanatomical and cognitive phenotype of individuals with neurodevelopmental disorders such as autism or schizophrenia. Our data showing that doxycycline and minocycline can reduce microglial activation, along with previous studies showing similar results in the adult hippocampus (Ekdahl et al., 2003; Monje et al., 2003), suggest the possibility that pharmacological agents could attenuate the impact of MIA on the developing fetal brain. Together, these data highlight the importance of understanding the normal homeostatic functions and pathogenic responses of microglial cells in the developing CNS.

\section{References}

Alliot F, Godin I, Pessac B (1999) Microglia derive from progenitors, originating from the yolk sac, and which proliferate in the brain. Brain Res Dev Brain Res 117:145-152. CrossRef Medline

Amaral DG, Schumann CM, Nordahl CW (2008) Neuroanatomy of autism. Trends Neurosci 31:137-145. CrossRef Medline

Andjelkovic AV, Nikolic B, Pachter JS, Zecevic N (1998) Macrophages/microglial cells in human central nervous system during development: an immunohistochemical study. Brain Res 814:13-25. CrossRef Medline

Ashwell K (1991) The distribution of microglia and cell death in the fetal rat forebrain. Brain Res Dev Brain Res 58:1-12. Medline 
Barrientos RM, Frank MG, Watkins LR, Maier SF (2012) Aging-related changes in neuroimmune-endocrine function: implications for hippocampaldependent cognition. Horm Behav 62:219-227. CrossRef Medline

Battista D, Ferrari CC, Gage FH, Pitossi FJ (2006) Neurogenic niche modulation by activated microglia: transforming growth factor beta increases neurogenesis in the adult dentate gyrus. Eur J Neurosci 23:83-93. CrossRef Medline

Bayer SA, Altman J (1991) Neocortical development. New York: Raven.

Biscaro B, Lindvall O, Tesco G, Ekdahl CT, Nitsch RM (2012) Inhibition of microglial activation protects hippocampal neurogenesis and improves cognitive deficits in a transgenic mouse model for Alzheimer's disease. Neurodegener Dis 9:187-198. CrossRef Medline

Brown AS, Begg MD, Gravenstein S, Schaefer CA, Wyatt RJ, Bresnahan M, Babulas VP, Susser ES (2004) Serologic evidence of prenatal influenza in the etiology of schizophrenia. Arch Gen Psychiatry 61:774-780. CrossRef Medline

Cai L, Hayes NL, Takahashi T, Caviness VS Jr, Nowakowski RS (2002) Size distribution of retrovirally marked lineages matches prediction from population measurements of cell cycle behavior. J Neurosci Res 69:731-744. CrossRef Medline

Carpentier PA, Palmer TD (2009) Immune influence on adult neural stem cell regulation and function. Neuron 64:79-92. CrossRef Medline

Courchesne E, Mouton PR, Calhoun ME, Semendeferi K, Ahrens-Barbeau C, Hallet MJ, Barnes CC, Pierce K (2011) Neuron number and size in prefrontal cortex of children with autism. JAMA 306:2001-2010. CrossRef Medline

Cowan WM, Fawcett JW, O'Leary DD, Stanfield BB (1984) Regressive events in neurogenesis. Science 225:1258-1265. CrossRef Medline

Dailey ME, Eyo U, Fuller L, Hass J, Kurpius D (2005) Imaging microglia in brain slices and slice cultures. In: Imaging in neuroscience (Helmchen F, Konnerth A, Yuste R, eds), pp 425-428. New York: Cold Spring Harbor.

d'Avila JC, Lam TI, Bingham D, Shi J, Won SJ, Kauppinen TM, Massa S, Liu J, Swanson RA (2012) Microglial activation induced by brain trauma is suppressed by post-injury treatment with a PARP inhibitor. J Neuroinflammation 9:31. CrossRef Medline

deAzevedo LC, Fallet C, Moura-Neto V, Daumas-Duport C, Hedin-Pereira C, Lent R (2003) Cortical radial glial cells in human fetuses: depthcorrelated transformation into astrocytes. J Neurobiol 55:288-298. CrossRef Medline

Delgado M, Ganea D (2003) Vasoactive intestinal peptide prevents activated microglia-induced neurodegeneration under inflammatory conditions: potential therapeutic role in brain trauma. FASEB J 17:1922-1924. Medline

Deverman BE, Patterson PH (2009) Cytokines and CNS development. Neuron 64:61-78. CrossRef Medline

Drabek T, Janata A, Jackson EK, End B, Stezoski J, Vagni VA, JaneskoFeldman K, Wilson CD, van Rooijen N, Tisherman SA, Kochanek PM (2012) Microglial depletion using intrahippocampal injection of liposome-encapsulated clodronate in prolonged hypothermic cardiac arrest in rats. Resuscitation 83:517-526. CrossRef Medline

Ekdahl CT, Claasen JH, Bonde S, Kokaia Z, Lindvall O (2003) Inflammation is detrimental for neurogenesis in adult brain. Proc Natl Acad Sci U S A 100:13632-13637. CrossRef Medline

Englund C, Fink A, Lau C, Pham D, Daza RA, Bulfone A, Kowalczyk T, Hevner RF (2005) Pax6, Tbr2, and Tbr1 are expressed sequentially by radial glia, intermediate progenitor cells, and postmitotic neurons in developing neocortex. J Neurosci 25:247-251. CrossRef Medline

Fan R, Xu F, Previti ML, Davis J, Grande AM, Robinson JK, Van Nostrand WE (2007) Minocycline reduces microglial activation and improves behavioral deficits in a transgenic model of cerebral microvascular amyloid. J Neurosci 27:3057-3063. CrossRef Medline

Fietz SA, Kelava I, Vogt J, Wilsch-Bräuninger M, Stenzel D, Fish JL, Corbeil D, Riehn A, Distler W, Nitsch R, Huttner WB (2010) OSVZ progenitors of human and ferret neocortex are epithelial-like and expand by integrin signaling. Nat Neurosci 13:690-699. CrossRef Medline

Fricker M, Neher JJ, Zhao JW, Théry C, Tolkovsky AM, Brown GC (2012) MFG-E8 mediates primary phagocytosis of viable neurons during neuroinflammation. J Neurosci 32:2657-2666. CrossRef Medline

Goings GE, Kozlowski DA, Szele FG (2006) Differential activation of microglia in neurogenic versus non-neurogenic regions of the forebrain. Glia 54:329-342. CrossRef Medline

Hagberg H, Gressens P, Mallard C (2012) Inflammation during fetal and neonatal life: implications for neurologic and neuropsychiatric disease in children and adults. Ann Neurol 71:444-457. CrossRef Medline

Hansen DV, Lui JH, Parker PR, Kriegstein AR (2010) Neurogenic radial glia in the outer subventricular zone of human neocortex. Nature 464:554-561. CrossRef Medline

Imai Y, Ibata I, Ito D, Ohsawa K, Kohsaka S (1996) A novel gene ibal in the major histocompatibility complex class III region encoding an EF hand protein expressed in a monocytic lineage. Biochem Biophys Res Commun 224:855-862. CrossRef Medline

Jantzie LL, Todd KG (2010) Doxycycline inhibits proinflammatory cytokines but not acute cerebral cytogenesis after hypoxia-ischemia in neonatal rats. J Psychiatry Neurosci 35:20-32. CrossRef Medline

Jantzie LL, Cheung PY, Todd KG (2005) Doxycycline reduces cleaved caspase-3 and microglial activation in an animal model of neonatal hypoxia-ischemia. J Cereb Blood Flow Metab 25:314-324. Medline

Javaherian A, Kriegstein A (2009) A stem cell niche for intermediate progenitor cells of the embryonic cortex. Cereb Cortex 19 [Suppl 1]:i70-i77. Medline

Kaur C, Dheen ST, Ling EA (2007) From blood to brain: amoeboid microglial cell, a nascent macrophage and its functions in developing brain. Acta Pharmacol Sin 28:1087-1096. CrossRef Medline

Kettenmann H, Hanisch UK, Noda M, Verkhratsky A (2011) Physiology of microglia. Physiol Rev 91:461-553. CrossRef Medline

Kigerl KA, Gensel JC, Ankeny DP, Alexander JK, Donnelly DJ, Popovich PG (2009) Identification of two distinct macrophage subsets with divergent effects causing either neurotoxicity or regeneration in the injured mouse spinal cord. J Neurosci 29:13435-13444. CrossRef Medline

Kreutzberg GW (1996) Microglia: a sensor for pathological events in the CNS. Trends Neurosci 19:312-318. CrossRef Medline

Kuida K, Haydar TF, Kuan CY, Gu Y, Taya C, Karasuyama H, Su MS, Rakic P, Flavell RA (1998) Reduced apoptosis and cytochrome c-mediated caspase activation in mice lacking caspase 9. Cell 94:325-337. CrossRef Medline

Kumamaru H, Saiwai H, Kobayakawa K, Kubota K, van Rooijen N, Inoue K, Iwamoto Y, Okada S (2012) Liposomal clodronate selectively eliminates microglia from primary astrocyte cultures. J Neuroinflammation 9:116. CrossRef Medline

Lai AY, Todd KG (2006) Hypoxia-activated microglial mediators of neuronal survival are differentially regulated by tetracyclines. Glia 53:809-816. CrossRef Medline

Li G, Kataoka H, Coughlin SR, Pleasure SJ (2009) Identification of a transient subpial neurogenic zone in the developing dentate gyrus and its regulation by Cxcl12 and reelin signaling. Development 136:327-335. CrossRef Medline

Lui JH, Hansen DV, Kriegstein AR (2011) Development and evolution of the human neocortex. Cell 146:18-36. CrossRef Medline

Maezawa I, Zimin PI, Wulff H, Jin LW (2011) Amyloid-beta protein oligomer at low nanomolar concentrations activates microglia and induces microglial neurotoxicity. J Biol Chem 286:3693-3706. CrossRef Medline

Martínez-Cerdeño V, Cunningham CL, Camacho J, Antczak JL, Prakash AN, Cziep ME, Walker AI, Noctor SC (2012) Comparative analysis of the subventricular zone in rat, ferret and macaque: evidence for an outer subventricular zone in rodents. PLoS One 7:e30178. CrossRef Medline

Meyer U (2013) Developmental neuroinflammation and schizophrenia. Prog Neuropsychopharmacol Biol Psychiatry, in press. Medline

Meyer U, Nyffeler M, Engler A, Urwyler A, Schedlowski M, Knuesel I, Yee BK, Feldon J (2006) The time of prenatal immune challenge determines the specificity of inflammation-mediated brain and behavioral pathology. J Neurosci 26:4752-4762. CrossRef Medline

Meyer U, Feldon J, Fatemi SH (2009) In-vivo rodent models for the experimental investigation of prenatal immune activation effects in neurodevelopmental brain disorders. Neurosci Biobehav Rev 33:1061-1079. CrossRef Medline

Monier A, Adle-Biassette H, Delezoide AL, Evrard P, Gressens P, Verney C (2007) Entry and distribution of microglial cells in human embryonic and fetal cerebral cortex. J Neuropathol Exp Neurol 66:372-382. CrossRef Medline

Monje ML, Toda H, Palmer TD (2003) Inflammatory blockade restores adult hippocampal neurogenesis. Science 302:1760-1765. CrossRef Medline

Morgan JT, Chana G, Pardo CA, Achim C, Semendeferi K, Buckwalter J, Courchesne E, Everall IP (2010) Microglial activation and increased mi- 
croglial density observed in the dorsolateral prefrontal cortex in autism. Biol Psychiatry 68:368-376. CrossRef Medline

Mosher KI, Andres RH, Fukuhara T, Bieri G, Hasegawa-Moriyama M, He Y, Guzman R, Wyss-Coray T (2012) Neural progenitor cells regulate microglia functions and activity. Nat Neurosci 15:1485-1487. CrossRef Medline

Neher JJ, Neniskyte U, Zhao JW, Bal-Price A, Tolkovsky AM, Brown GC (2011) Inhibition of microglial phagocytosis is sufficient to prevent inflammatory neuronal death. J Immunol 186:4973-4983. CrossRef Medline

Neher JJ, Neniskyte U, Brown GC (2012) Primary phagocytosis of neurons by inflamed microglia: potential roles in neurodegeneration. Front Pharmacol 3:27. Medline

Nelson KB, Grether JK, Croen LA, Dambrosia JM, Dickens BF, Jelliffe LL, Hansen RL, Phillips TM (2001) Neuropeptides and neurotrophins in neonatal blood of children with autism or mental retardation. Ann Neurol 49:597-606. CrossRef Medline

Noctor SC (2011) Time-lapse imaging of fluorescently labeled live cells in the embryonic mammalian forebrain. Cold Spring Harbor Protoc 2011: 341-355. CrossRef Medline

Noctor SC, Flint AC, Weissman TA, Dammerman RS, Kriegstein AR (2001) Neurons derived from radial glial cells establish radial units in neocortex. Nature 409:714-720. CrossRef Medline

Noctor SC, Flint AC, Weissman TA, Wong WS, Clinton BK, Kriegstein AR (2002) Dividing precursor cells of the embryonic cortical ventricular zone have morphological and molecular characteristics of radial glia. J Neurosci 22:3161-3173. Medline

Noctor SC, Martínez-Cerdeño V, Ivic L, Kriegstein AR (2004) Cortical neurons arise in symmetric and asymmetric division zones and migrate through specific phases. Nat Neurosci 7:136-144. CrossRef Medline

Noctor SC, Martínez-Cerdeño V, Kriegstein AR (2008) Distinct behaviors of neural stem and progenitor cells underlie cortical neurogenesis. J Comp Neurol 508:28-44. CrossRef Medline

Oertel-Knöchel V, Knöchel C, Rotarska-Jagiela A, Reinke B, Prvulovic D, Haenschel C, Hampel H, Linden DE (2012) Association between psychotic symptoms and cortical thickness reduction across the schizophrenia spectrum. Cereb Cortex 23:61-70. CrossRef Medline

Olah M, Biber K, Vinet J, Boddeke HW (2011) Microglia phenotype diversity. CNS and neurological disorders drug targets 10:108-118. CrossRef Medline

Paolicelli RC, Bolasco G, Pagani F, Maggi L, Scianni M, Panzanelli P, Giustetto M, Ferreira TA, Guiducci E, Dumas L, Ragozzino D, Gross CT (2011) Synaptic pruning by microglia is necessary for normal brain development. Science 333:1456-1458. CrossRef Medline

Pelvig DP, Pakkenberg H, Stark AK, Pakkenberg B (2008) Neocortical glial cell numbers in human brains. Neurobiol Aging 29:1754-1762. CrossRef Medline

Pont-Lezica L, Béchade C, Belarif-Cantaut Y, Pascual O, Bessis A (2011) Physiological roles of microglia during development. J Neurochem 119: 901-908. CrossRef Medline

Rais M, Cahn W, Schnack HG, Hulshoff Pol HE, Kahn RS, van Haren NE (2012) Brain volume reductions in medication-naive patients with schizophrenia in relation to intelligence quotient. Psychol Med 42:18471856. Medline

Rakic P (1974) Neurons in rhesus monkey visual cortex: systematic relation between time of origin and eventual disposition. Science 183:425-427. CrossRef Medline

Rakic P (2009) Evolution of the neocortex: a perspective from developmental biology. Nat Rev Neurosci 10:724-735. CrossRef Medline

Rezaie P, Male D (1999) Colonisation of the developing human brain and spinal cord by microglia: a review. Microsc Res Tech 45:359-382. CrossRef Medline

Saijo K, Glass CK (2011) Microglial cell origin and phenotypes in health and disease. Nat Rev Immun 11:775-787. CrossRef

Savill J, Fadok V (2000) Corpse clearance defines the meaning of cell death. Nature 407:784-788. CrossRef Medline

Schafer DP, Lehrman EK, Kautzman AG, Koyama R, Mardinly AR, Yamasaki R, Ransohoff RM, Greenberg ME, Barres BA, Stevens B (2012) Micro- glia sculpt postnatal neural circuits in an activity and complementdependent manner. Neuron 74:691-705. CrossRef Medline

Schmechel DE, Rakic P (1979) A Golgi study of radial glial cells in developing monkey telencephalon: morphogenesis and transformation into astrocytes. Anat Embryol 156:115-152. CrossRef Medline

Sica A, Mantovani A (2012) Macrophage plasticity and polarization: in vivo veritas. J Clin Invest 122:787-795. CrossRef Medline

Sierra A, Encinas JM, Deudero JJ, Chancey JH, Enikolopov G, OverstreetWadiche LS, Tsirka SE, Maletic-Savatic M (2010) Microglia shape adult hippocampal neurogenesis through apoptosis-coupled phagocytosis. Cell Stem Cell 7:483-495. CrossRef Medline

Smart IH, Dehay C, Giroud P, Berland M, Kennedy H (2002) Unique morphological features of the proliferative zones and postmitotic compartments of the neural epithelium giving rise to striate and extrastriate cortex in the monkey. Cereb Cortex 12:37-53. CrossRef Medline

Spencer SJ, Auer RN, Pittman QJ (2006) Rat neonatal immune challenge alters adult responses to cerebral ischaemia. J Cereb Blood Flow Metab 26:456-467. Medline

Stolp HB, Turnquist C, Dziegielewska KM, Saunders NR, Anthony DC, Molnár Z (2011) Reduced ventricular proliferation in the foetal cortex following maternal inflammation in the mouse. Brain 134:3236-3248. CrossRef Medline

Stubbs D, DeProto J, Nie K, Englund C, Mahmud I, Hevner R, Molnar Z (2009) Neurovascular congruence during cerebral cortical development. Cereb Cortex 19 [Suppl 1]:i32-i41. Medline

Swinnen N, Smolders S, Avila A, Notelaers K, Paesen R, Ameloot M, Brone B, Legendre P, Rigo JM (2012) Complex invasion pattern of the cerebral cortex bymicroglial cells during development of the mouse embryo. Glia 61:150-163. CrossRef Medline

Tarassishin L, Suh HS, Lee SC (2011) Interferon regulatory factor 3 plays an anti-inflammatory role in microglia by activating the PI3K/Akt pathway. J Neuroinflammation 8:187. CrossRef Medline

Tikka T, Fiebich BL, Goldsteins G, Keinanen R, Koistinaho J (2001) Minocycline, a tetracycline derivative, is neuroprotective against excitotoxicity by inhibiting activation and proliferation of microglia. J Neurosci 21: 2580-2588. Medline

Tremblay MÈ, Stevens B, Sierra A, Wake H, Bessis A, Nimmerjahn A (2011) The role of microglia in the healthy brain. J Neurosci 31:16064-16069. CrossRef Medline

Välimäki MJ, Laitinen K, Patronen A, Puolijoki H, Seppänen J, Pylkkänen L, Aranko SM, Sairanen S, Blåfield H, Rekiaro M, Väisänen K, Kormano M, Mäkinen L, Salmi J, Ala-Kaila K, Perttilä J, Vesterinen K, Koivunoro K, Koivunoro K (2002) Prevention of bone loss by clodronate in early postmenopausal women with vertebral osteopenia: a dose-finding study. Osteoporos Int 13:937-947. CrossRef Medline

Van Kooten IA, Palmen SJ, von Cappeln P, Steinbusch HW, Korr H, Heinsen H, Hof PR, van Engeland H, Schmitz C (2008) Neurons in the fusiform gyrus are fewer and smaller in autism. Brain 131:987-999. CrossRef Medline

Van Rooijen N, Sanders A (1994) Liposome mediated depletion of macrophages: mechanism of action, preparation of liposomes and applications. J Immunol Methods 174:83-93. CrossRef Medline

Verney C, Monier A, Fallet-Bianco C, Gressens P (2010) Early microglial colonization of the human forebrain and possible involvement in periventricular white-matter injury of preterm infants. J Anatomy 217:436-448. CrossRef

Voigt T (1989) Development of glial cells in the cerebral wall of ferrets: direct tracing of their transformation from radial glia into astrocytes. J Comp Neurol 289:74-88. CrossRef Medline

Wu Y, Tibrewal N, Birge RB (2006) Phosphatidylserine recognition by phagocytes: a view to a kill. Trends Cell Biol 16:189-197. CrossRef Medline

Yrjänheikki J, Keinänen R, Pellikka M, Hökfelt T, Koistinaho J (1998) Tetracyclines inhibit microglial activation and are neuroprotective in global brain ischemia. Proc Natl Acad Sci U S A 95:15769-15774. CrossRef Medline

Ziv Y, Ron N, Butovsky O, Landa G, Sudai E, Greenberg N, Cohen H, Kipnis J, Schwartz M (2006) Immune cells contribute to the maintenance of neurogenesis and spatial learning abilities in adulthood. Nat Neurosci 9:268-275. CrossRef Medline 